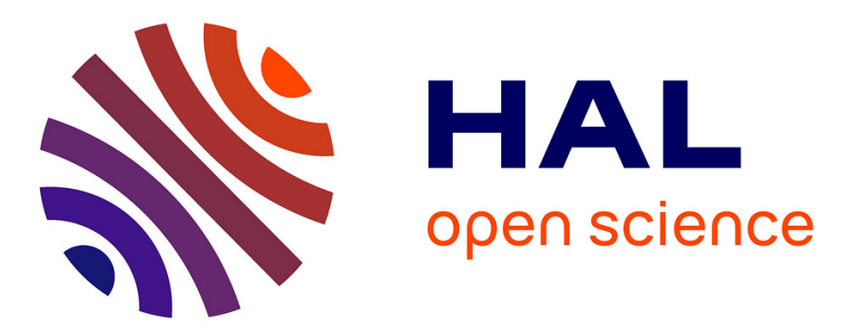

\title{
Chiral recognition in a single molecule: A study of homo and heterochiral butan-2,3-ol by Fourier transform microwave spectroscopy \\ Brian John Howard
}

\section{- To cite this version:}

Brian John Howard. Chiral recognition in a single molecule: A study of homo and heterochiral butan2,3-ol by Fourier transform microwave spectroscopy. Molecular Physics, 2007, 105 (05-07), pp.825-839. 10.1080/00268970701241649 . hal-00513083

\section{HAL Id: hal-00513083 \\ https://hal.science/hal-00513083}

Submitted on 1 Sep 2010

HAL is a multi-disciplinary open access archive for the deposit and dissemination of scientific research documents, whether they are published or not. The documents may come from teaching and research institutions in France or abroad, or from public or private research centers.
L'archive ouverte pluridisciplinaire HAL, est destinée au dépôt et à la diffusion de documents scientifiques de niveau recherche, publiés ou non, émanant des établissements d'enseignement et de recherche français ou étrangers, des laboratoires publics ou privés. 


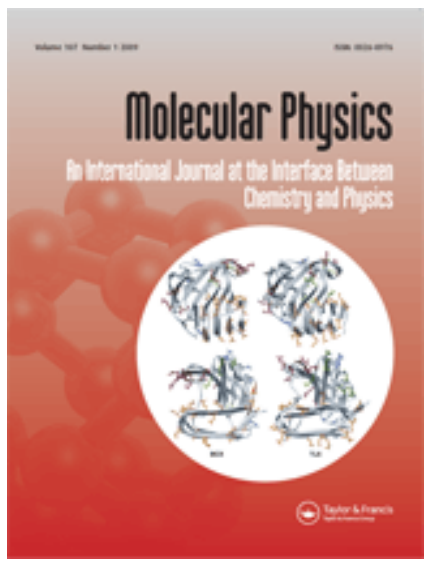

Chiral recognition in a single molecule: A study of homo and heterochiral butan-2,3-ol by Fourier transform microwave spectroscopy

\begin{tabular}{|r|l|}
\hline Journal: & Molecular Physics \\
\hline Manuscript ID: & TMPH-2006-0045.R1 \\
\hline Manuscript Type: & Full Paper \\
\hline Date Submitted by the \\
Author: & 22-Jan-2007 \\
\hline Complete List of Authors: & Howard, Brian; Oxford University, Department of Chemistry \\
\hline Keywords: & $\begin{array}{l}\text { chiral discrimination, microwave spectroscopy, intramolecular } \\
\text { interactions, chirality, conformations }\end{array}$ \\
\hline
\end{tabular}

\section{今 scholaronE" \\ Manuscript Central}


Chiral recognition in a single molecule: A study of homo and heterochiral butan-2,3-diol by Fourier transform microwave spectroscopy.

\title{
J. Paul I. Hearn and Brian J. Howard.
}

Physical and Theoretical Chemistry Laboratory

Department of Chemistry

Oxford University

South Parks Road

Oxford, OX1 3QZ

United Kingdom

\author{
Author for correspondence : \\ Professor Brian. J. Howard \\ Physical and Theoretical Chemistry Laboratory \\ South Parks Road \\ Oxford, OX1 3QZ \\ United Kingdom
}

Telephone : +441865275438

Fax : $\quad+441865275410$

E-mail: brian.howard@chem.ox.ac.uk

Running title: microwave spectroscopy of butandiol 


\begin{abstract}
The microwave Fourier transform spectrum of butan-2,3-ol has been recorded in the range 5$18 \mathrm{GHz}$. The molecule possesses two chiral centres and exists in two distinct forms, one of which is homochiral $((R, R)$ or $(S, S))$ and is overall chiral, and the other which is heterochiral $((R, S)$ or $(S, R))$ and is overall meso. Detailed ab initio calculations enabled investigation of the relative stability of the many conformations exhibited by each form of the molecule. It is shown that the lowest energy forms in each case possess an internal hydrogen bond. The spectrum of the heterochiral (meso) form could be readily identified and analysed. The homochiral form, however, exhibits a tunnelling motion of about $1 \mathrm{GHz}$, in which the hydrogen bonded $\mathrm{OH}$ groups interchange their roles. Deuteration of one of these $\mathrm{OH}$ protons quenches the tunnelling motion, aiding the assignment of the spectrum. In all cases, deuteration of the hydroxyl groups was used to locate the positions of the $\mathrm{OH}$ hydrogen atoms and helped to confirm the identification of the conformers present.
\end{abstract}




\section{Introduction}

Butan-2,3-diol, is a fascinating molecule. It possesses two chiral centres and hence, exists as two pairs of enantiomers. These enantiomeric pairs differ only in their chirality, but should have very different properties. The lowest conformers in energy exhibit an intramolecular hydrogen bond, which should pronounce the chiral recognition effect in the molecule. Most interesting of all, however, the chiral recognition will affect the dynamic properties, as well as the rigid structure, because of the symmetries of the different isomers.

A considerable volume of work has been carried out on butan-2,3-diol. The conformations of chiral $(R, R$ and $S, S)$ and meso-butan-2,3-diol $(R, S)$ in $\mathrm{CCl}_{4}$ were compared by Kuhn $[1,2]$ via infrared spectroscopy. He concluded that the ratio of hydrogen bonded and non-hydrogen bonded $\mathrm{OH}$ was larger for the chiral species. This has been explained in terms of the steric interaction of the methyl groups. The chiral species can form an intramolecular hydrogen bond when the two methyl groups are trans to one another, but the hydroxyl groups in the meso species may only interact in this way when the methyl groups are forced into a gauche conformation (see figure 1). Kuhn also deduced that a stronger hydrogen bond was present in the chiral molecule by comparing the splittings between the free and bonded $\mathrm{OH}$ peaks.

Beyond the desire to study hydrogen bonding and chiral recognition, the stereochemistry of many molecules have been related to $(2 R, 3 R)$-butan-2,3-diol and its derivatives [3-6]. The conformational properties of this isomer are also of interest as it has been used as a model for investigations of the methyl ester of $(R, R)$-tartaric acid monoamide [7]. An investigation by Wang et al. [8] utilized infrared spectroscopy and ab initio molecular orbital calculations to probe the conformational properties of this isomer in the solution phase. These authors found that the gauche hydrogen bonded conformation of the chiral molecule was more stable than the trans conformer, in disagreement with the work of Kuhn $[1,2]$. 
There has been recent interest in the conformations of other glycol molecules. The microwave spectra of asymmetrically deuterated forms of ethylene glycol were first assigned by Caminati et al. in $1981[9,10]$, but attempts to assign the spectrum of the parent isotopomer concluded that the molecule exhibits a large amplitude motion, which produces a tunnelling splitting in the spectrum and complicates the analysis $[11,12]$. Recently, however, Christen et al. have recorded microwave spectra of two conformers of ethylene glycol [13-16]. They found that the tunnelling splittings in the observed conformers were approximately $7 \mathrm{GHz}$ and 1.4 GHz. Microwave spectra of two conformers of propan-1,2-diol were also studied by Caminati [17]. The spectra of these species were re-examined recently, and a third conformer was assigned, which was found to be the global minimum for the molecule [18].

This paper presents the first assignment of the microwave spectra of the ground state conformers of chiral and meso butan-2,3-diol. This work has been augmented with an ab initio study, which has been used to provide geometrical predictions and to help decide which spectra arise from which conformers.

\section{The structure of butan-2,3-diol}

The butan-2,3-diol molecule has conformational flexibility about three bonds; different conformers may be generated by rotations about the central, $\mathrm{C}_{2}-\mathrm{C}_{3}$, bond or either of the two $\mathrm{C}-\mathrm{O}$ bonds, so the molecule possesses $3^{3}=27$ conformers. In addition, the presence of two chiral centres gives rise to four forms of the molecule, namely the $(R, R),(S, S),(R, S)$ and $(S$, $R$ ) configurations. Microwave spectroscopy will distinguish only the homo and heterochiral forms of the molecule, so the ab initio study reviewed below considers $27 \times 2$ species. Initial geometry optimizations were performed on these systems with the Gaussian 98 package [19] at the HF/6-311G level. The geometries of the conformers lying lowest in energy were then reoptimized at the MP2/6-311++G** level. 


\subsection{The heterochiral species}

The 27 conformers of $(R, S)$ and $(S, R)$-butan-2,3-diol have been classified with a nomenclature of the form $X Y Z$. The nomenclature used for both the hetero and homochiral species is illustrated in figure 2.

" $X$ " represents the geometry of the carbon chain, and is assigned as follows; if the two methyl groups are trans to one another $X=\mathrm{T}$. If the two methyl groups are gauche to one another $X=\mathrm{G}_{\mathrm{r}}$ or $\mathrm{G}_{1}$. These two gauche orientations of the carbon chain are mirror images of one another. If the methyl and hydroxyl groups trans to one another are in the vertical plane, the methyl group points downwards and the molecule is viewed from the end nearest this methyl group, the classification is $\mathrm{G}_{\mathrm{r}}$ if the methyl group and hydroxyl group gauche to one another are on the right hand side. If this positioning of the trans methyl and hydroxyl groups leaves the remaining methyl and hydroxyl groups on the left, the classification is $\mathrm{G}_{1}$.

" $Y$ " denotes the position of the hydroxyl group, which is trans to the methyl group on the other chiral carbon atom. If the carbon chain is in the $\mathrm{T}$ position the two hydroxyl groups are equivalent and the labels " $Y$ " and ' $Z$ ' are interchangeable. The classification then considers the position of the $\mathrm{O}-\mathrm{H}$ bond relative to the groups attached to the chiral carbon to which the hydroxyl group is bonded. $X=\mathrm{M}$ if the $\mathrm{O}-\mathrm{H}$ bond is trans to the methyl group, $\mathrm{C}$ if the $\mathrm{O}-\mathrm{H}$ bond is trans to the carbon chain or $\mathrm{H}$ if it is trans to the hydrogen atom.

" $Z$ ' is classified in the same way as " $Y$ ", but denotes the position of the remaining hydroxyl group, which is gauche to the methyl group on the other chiral carbon atom.

Of these twenty-seven conformers nineteen were minima on the HF/6-311G potential surface (see table 1). These nineteen minima comprised all nine conformations where the methyl groups were trans to one another and five of each of the two gauche conformations. The minima were grouped in eight pairs of mirror images; the five $\mathrm{G}_{\mathrm{r}} Y Z$ minima being mirror 
images of the five $\mathrm{G}_{1} Z Y$ minima and the trans conformers also forming mirror pairs $(\mathrm{THC} \equiv \mathrm{TCH}),(\mathrm{TMC} \equiv \mathrm{TCM})$ and $(\mathrm{TMH} \equiv \mathrm{THM})$. Only the TCC, TMM and THH conformers are unique.

As one would expect, the four mirror pairs of conformers that display an intramolecular hydrogen bond tend to be the lowest in energy. These species, and the TCC conformer, were chosen for re-optimization at the MP2/6-311++G** level, which yielded the rotational constants, relative energies and dipole moments displayed in table 2 . The only large change during the re-optimization was the drop in energy of the GMM conformer. This was due to a large change in the angular orientation of the hydroxyl groups, resulting presumably from the inclusion of polarization functions in the basis set.

\subsection{The homochiral species}

The 27 conformers of $(R, R)$ and $(S, S)$-butan-2,3-diol have been classified in a similar manner to that described above, for the heterochiral molecule. As for the heterochiral species, the nomenclature is of the form $X Y Z$.

" $X$ " represents the geometry of the carbon chain. If the two methyl groups are trans to one another $X=\mathrm{T}$. If the two methyl groups are gauche to one another $X=\mathrm{Gg}$ or Gt. These two gauche conformations of the carbon chain are non-equivalent and differ in that both methyl groups are either trans $(\mathrm{Gt})$ or gauche $(\mathrm{Gg})$ to both hydroxyl groups.

Since the two hydroxyl groups are both either gauche or trans to the two methyl groups, for a specific orientation about the central C-C bond, they are equivalent. Hence, there is no way to distinguish between them, and " $Y$ " and " $Z$ " are interchangeable. As for the heterochiral molecule, $Y$ or $Z=\mathrm{M}$ if the $\mathrm{O}-\mathrm{H}$ bond is trans to the methyl group, $\mathrm{C}$ if the $\mathrm{O}-\mathrm{H}$ bond is trans to the carbon chain or $\mathrm{H}$ if it is trans to the hydrogen atom. 
Twenty-three of the twenty-seven starting structures are minima on the HF/6-311G potential surface (see table 3). The equivalence of the two hydroxyl groups means that nine of the twenty seven starting conformers are unique, and that there are nine identical pairs. For instance, for the $\mathrm{Gg}$ carbon chain rotamers, the $\mathrm{GgMM}, \mathrm{GgHH}$ and $\mathrm{GgCC}$ conformers are unique and the $(\mathrm{GgMC} \equiv \mathrm{GgCM}),(\mathrm{GgMH} \equiv \mathrm{GgHM})$ and $(\mathrm{GgHC} \equiv \mathrm{GgCH})$ are the identical pairs. Of the twenty-three minima from the ab initio calculations, there are 7 unique conformers and 8 identical pairs. As in the heterochiral molecule, all conformers of the carbon chain orientation in which hydrogen bonding cannot occur $(\mathrm{Gg})$, were minima. Of the T-type carbon chain conformers there were three pairs and two unique structures. Two of these pairs, the THC and THM rotamers, exhibit an intramolecular hydrogen bond. The remaining two minima and two pairs were Gt-type rotamers. Both pairs of Gt-type minima possess a hydrogen bond,and it was these conformers that were found to be the lowest in energy of all. The results of MP2 calculations are given in table 4. This is in agreement with the ab initio study of Wang et al. [8], but contradicts the arguments given in references 1 and 2.

It is interesting to consider the calculated energy differences between the hetero and homochiral forms of butan-2,3-diol. The GtCM homochiral conformer has an energy about 60 $\mathrm{cm}^{-1}$ lower than the $\mathrm{G}_{\mathrm{l}} \mathrm{CM}$ and $\mathrm{G}_{\mathrm{r}} \mathrm{MC}$ heterochiral conformers. It seems likely that this energy difference arises for steric reasons; the projections of the conformers in figures 3 and 4 show that the sum of the angles between the bulky groups about the central C-C bond is only $180^{\circ}$ in the four lowest heterochiral conformers, but is $270^{\circ}$ in the two lowest homochiral conformers. The projections also show that the hydrogen bond in the GtCM conformer may be shortened by an increase in the separation of the two methyl groups, but in the $\mathrm{G}_{1} \mathrm{CM}$ and $\mathrm{G}_{\mathrm{r}} \mathrm{MC}$ conformers the methyl group separation must decrease to shorten the hydrogen bond. Thus we might expect to find a stronger hydrogen bond in the homochiral species. 


\section{Experimental details}

Microwave transitions of butan-2,3-diol were recorded with the Fourier transform spectrometer which has been described previously [20]. The sample was heated to about $70^{\circ} \mathrm{C}$, in order to produce an appropriate concentration of butan-2,3-diol and the nozzle to about $75^{\circ} \mathrm{C}$ to prevent blocking. Helium at 1.5 bar was used as the backing gas for all spectroscopic investigations.

Samples of meso $((R, S),(S, R))$ and racemic $((R, R),(S, S),(R, S),(S, R))$-butan-2,3diol were purchased from Sigma-Aldrich. A chiral sample of $(R, R)$-butan-2,3-diol was also acquired, from Acrōs Organics. The hydroxyl groups of the racemic sample were deuterated by distilling a mixture of $25 \mathrm{ml}$ of butan-2,3-diol and $10 \mathrm{ml}$ of $\mathrm{D}_{2} \mathrm{O}$. This procedure was only performed once, as the aim was to maximise the quantities of the mono-deutero-diols.

\subsection{Experimental results I: Heterochiral butan-2,3-diol}

The first spectra recorded were obtained by scanning over frequency ranges of about $200 \mathrm{MHz}$ around the predicted $0_{00}-1_{11}, 1_{01}-2_{12}, 2_{02}-3_{13}$ and $2_{11}-3_{03}$ transitions of the $\mathrm{G}_{1} \mathrm{CM}$ and $\mathrm{G}_{\mathrm{r}} \mathrm{MC}$ conformers of $(R, S)$-butan-2,3-diol. Several strong transitions were found in each frequency range but rotational constants derived from the set of four lines that gave the best fit to a rigid asymmetric top Hamiltonian enabled the $1_{01}-2_{02}$ and $3_{13}-3_{22}$ transitions to be accurately predicted. A further 46 lines were then recorded. All lines were fitted to a Watson A-type rotational Hamiltonian [21]. The fits are summarized in table 5.

The initial scans had been made with the racemic mixture of butan-2,3-diol so the assignment of the transitions to the heterochiral molecule was confirmed with the pure samples; it was found that the assigned transitions could be observed with the meso $(R, S$ and $S, R)$ sample but not with the chiral $(R, R)$ sample. 
The next search focussed on the microwave spectra of the two mono-deutero-hydroxyl forms of the $\mathrm{G}_{l} \mathrm{CM}$ and $\mathrm{G}_{\mathrm{r}} \mathrm{MC}$ conformers. It was desirable to obtain information on these species as it was hoped that a Kraitchman analysis [22] of the rotational constants would confirm the assignment of the conformer to one of the ab initio predictions. It is likely that the errors between the $a b$ initio predictions and experimental rotational constants are similar for the parent and deuterated isotopomers. Hence, assuming that the conformer already observed was the $\mathrm{G}_{1} \mathrm{CM} / \mathrm{G}_{\mathrm{r}} \mathrm{MC}$ species, it should be possible to improve the ab initio predictions of the rotational constants of the mono-deutero-hydroxyl species by comparison with the $a b$ initio and experimental data on the parent isotopomer.

This predictive technique appeared to work, and allowed microwave spectra of two species with rotational constants similar to that of the parent isotopomer to be recorded. The transitions of these species exhibited narrow quadrupole splittings, arising because of the presence of the deuterium atom, which has a quadrupolar nucleus with a spin of 1 . The transitions of these species were fitted to a Hamiltonian identical to that used for the parent isotopomer except that it included the diagonal quadrupole coupling parameters, $\chi_{a a}$ and $\chi_{b b}$ $\chi_{c c}$. In total, 17 rotational transitions consisting of 47 hyperfine components were fitted for the isotopomer which was believed to have the proton accepting hydroxyl group deuterated and 17 rotational transitions consisting of 56 hyperfine components for the for the isotopomer which was believed to be deuterated at the proton donating hydroxyl group. The resulting spectral parameters are given in table 5.

\subsection{Experimental results II: Homochiral butan-2,3-diol}

Initial searches for the spectra of the GtCM homochiral conformer did not lead to a convincing assignment. This was believed to be due to a tunnelling motion of the hydroxyl groups that could connect two equivalent minima of any of the four lowest energy conformers 
of homochiral butan-2,3-diol. Hence, scans were performed to locate the spectra of the two mono-deutero-hydroxyl species, as the asymmetric deuteration should remove any effect of such tunnelling on the spectrum. It was hoped that the spectra of these deuterated species would yield accurate estimates of the rotational constants of the parent isotopomer.

Searches around the $a b$ initio predicted microwave transition frequencies for the deuterated isotopomers of the GtCM conformer yielded two sets of spectra. As for the heterochiral species, narrow hyperfine splittings resulting from the quadrupole moment of the deuterium nucleus were observable. Ten rotational transitions, divided into 26 hyperfine components, of each of these species were fitted to Watson A-type Hamiltonians. The spectral parameters are listed in table 6.

\subsection{The tunnelling spectrum of homochiral butan-2,3-diol}

As in the $\mathrm{g}^{\prime} \mathrm{Ga}$ conformer of ethylene glycol, the GtCM conformer of homochiral butan-2,3-diol was expected to undergo a tunnelling motion that reverses the direction of the $\mu_{\mathrm{a}}$ and $\mu_{c}$ components of the dipole moment. Thus, the a and c-type microwave transitions should connect the two tunnelling states of the GtCM conformer, and these transitions should occur at frequencies approximately equal to a pure rotational transition difference plus or minus a tunnelling splitting. The b-type transitions link energy levels of the same tunnelling state and should be largely independent of the tunnelling splitting. The tunnelling motion is illustrated in figure 5.

Coriolis forces complicate the spectrum by making the tunnelling splitting dependent on the rotational state of the molecule. If the spectrum of a molecule exhibiting a tunnelling motion through a potential barrier such as ethylene glycol or butan-2,3-diol is analysed with a rigid rotor approach then the rotational constants obtained will relate to the transition state, as this is the average structure. Hence, when the molecules are at their geometrical minima there 
are off-diagonal terms in the inertia tensors. In the rotational Hamiltonian, the rotational constants are the coefficients of the squares of the components of the total angular momentum. The off-diagonal inertial terms are the coefficients of the cross products of the angular momentum components.

Two methods that have been developed to account for these effects are the internal axis method (IAM) of Hougen [23, 24] and the reduced axis system (RAS) of Pickett [25]. The IAM approach removes the tunnelling-rotation mixing via a suitable choice of axes and thus considers the wavefunctions of the two vibrational species to be localized in their potential wells. The IAM Hamiltonian contains a constant term for the tunnelling between the wells and coupling terms to take account of the dependence of the tunnelling on the rotational state. The RAS technique solves the problem including the tunnelling-rotation mixing via a stepwise diagonalization of the Hamiltonian matrix. Thus, the RAS technique considers the symmetric and antisymmetric tunnelling states and the terms involving the cross products of the angular momentum components. The RAS Hamiltonian is of the form:

$$
\begin{aligned}
& \hat{\mathbf{H}}_{v v}=E_{v}+A J_{a}^{2}+B J_{b}^{2}+C J_{c}^{2} \\
& \hat{\mathbf{H}}_{v v^{\prime}}=\left(F_{b c}\left(J_{b} J_{c}+J_{c} J_{b}\right)\right)+\left(F_{a b}\left(J_{a} J_{b}+J_{b} J_{a}\right)\right)+\left(F_{a c}\left(J_{a} J_{c}+J_{c} J_{a}\right)\right)
\end{aligned}
$$

where $E_{v}$ is the energy of the vibrational state, $\hat{\mathbf{H}}_{v v}$ connects levels of the same vibrational state and $\hat{\mathbf{H}}_{v v^{\prime}}$ connects levels of different vibrational states. Pickett has determined the required symmetric top matrix elements for equations 1 and 2, which are given in reference 25.

Christen et al. have employed both the IAM and RAS methods for their work on ethylene glycol [13 - 16]. The main advantages of the RAS method are that it can provide information on the tunnelling splitting even if no transitions across the tunnelling splitting have been recorded and that it can be applied without knowledge of the tunnelling path, whereas the IAM method must be set up differently for each tunnelling path considered. For 
these reasons the analysis of homochiral butan-2,3-diol presented in this chapter has utilized the RAS method, implemented with the SPFIT computer program of Pickett [26].

A useful diagnostic, which aids the assignment of microwave spectra, occurs when it is possible to observe "cycles" of transitions, which link two rotational energy levels by more than one path. If the assignment of the transitions is correct, the sum of the transition frequencies in each path should be equal to within the experimental error.

The predicted rotational constants provided by work on the mono-deutero-hydroxyl species indicated that two cycles of b-type transitions lay within the range of the spectrometer. Scans over frequency ranges centred on the predictions of these transitions yielded four cycles in total. These sixteen transitions were then fitted to an RAS Hamiltonian that included a set of rotational constants for each of the two tunnelling states, a tunnelling frequency and the Coriolis coupling constants $F_{a b}$ and $F_{b c}$.

Only two combinations of trial fits were then needed to deduce which two cycles of lines belonged to the lower, and which to the upper, tunnelling state. The cycles are illustrated in figure 6. A reasonable starting value of the tunnelling splitting $\left(\Delta_{t u n}\right)$ was deduced by fitting the sixteen transitions with values of $\Delta_{\text {tun }}$ between 0 and $7 \mathrm{GHz}$ in $0.5 \mathrm{GHz}$ steps. It was found that starting values of 1.0 and $1.5 \mathrm{GHz}$ both yielded a fit with a root mean square error of 9.6 $\mathrm{kHz}$ and $\Delta_{\text {tun }}=1024.39(65) \mathrm{MHz}$. The small error of this fit appeared to confirm that the two pairs of cycles had been correctly matched.

Using the parameters from this fit it proved possible to record transitions across the tunnelling; 20 a-type and 12 c-type transitions were found. A further 48 b-type lines were also observed and included in the final fit.

The five A-reduced quartic centrifugal distortion terms were also derived from this fit but, the differences between the centrifugal distortion constants of the two tunnelling states 


\section{Discussion}

\subsection{Mass substitution analysis}

The position of a specific atom within a molecule may be deduced if the rotational constants, which arise when different isotopes are present at this position, are known. This is achieved via Kraitchman's substitution method [22]. This technique will be utilized below in an attempt to confirm which of the ab initio structures most closely resembles the species that have been observed in the supersonic molecular beam. The difference in the moment of inertia between two isotopomers may be written [27]:

$$
\Delta I_{i}=\left(\frac{m \Delta m}{m+\Delta m}\right) r_{i}^{2}
$$

where $\Delta I_{i}$ is the difference in the $a, b$ or $c$ moment of inertia of the two species, $m$ is the mass of the parent species (approximately $90 \mathrm{u}$ in the case of butan-2,3-diol), $\Delta m$ is the change of mass involved in the substitution (approximately $1 \mathrm{u}$ for $\mathrm{H}$ substituted by D) and $r_{i}$ is the distance of the substituted atom from the principal axis to which $\Delta I_{i}$ relates.

This analysis assumes that the observed structures are not affected by the mass dependence of the vibrations of the molecule and also that the inertial axes are not significantly shifted by the change in mass. Co-ordinates relative to the three principal axes were thus deduced for the two hydrogen atoms in the observed homo and heterochiral conformers of butan-2,3-diol, and are displayed in tables 8 and 9 alongside the equivalent $a b$ initio results for the conformers predicted to have the lowest energies.

The experimental results for the two conformers match very well with the co-ordinates for the lowest energy homo and heterochiral conformers respectively. As can be seen from 
figures 3 and 4, the only significant difference between the GtCM and GtMH homochiral conformers and the $\mathrm{G}_{1} \mathrm{CM} / \mathrm{G}_{\mathrm{r}} \mathrm{MC}$ and $\mathrm{G}_{\mathrm{l}} \mathrm{MM} / \mathrm{G}_{\mathrm{r}} \mathrm{MM}$ heterochiral conformers is a rotation of the HOCC dihedral angle for the proton accepting $\mathrm{OH}$ group. The coordinates above reflect this; as expected, it is only the coordinates of the proton acceptor hydroxyl hydrogen that allow us to distinguish which conformer of each of these pairs has been observed.

The predicted dipole moment components of the heterochiral conformers, displayed in table 2, also support the conclusion that the $\mathrm{G}_{\mathrm{l}} \mathrm{CM} / \mathrm{G}_{\mathrm{r}} \mathrm{MC}$ conformer is the one observed. In both the $\mathrm{G}_{\mathrm{l}} \mathrm{HC} / \mathrm{G}_{\mathrm{r}} \mathrm{CH}$ and the $\mathrm{G}_{\mathrm{l}} \mathrm{MM} / \mathrm{G}_{\mathrm{r}} \mathrm{MM}$ conformers two of the dipole components are small. There is no way to measure the dipoles quantitatively in the microwave experiment that has been performed, but the fact the $\mathrm{a}, \mathrm{b}$ and c-type transitions were all easily observable suggests that none of the dipole components were near zero. In the homochiral conformer the lowest energy ab initio structures all have similar dipoles and do not add further evidence to support the Kraitchman analysis

\subsection{Deuterium quadrupole coupling constants}

The inertial axis quadrupole coupling constants obtained from the microwave spectra provide information on the effect of the hydrogen bond on the hydroxyl groups in butan-2,3diol. These coupling constants are elements of the inertial axis quadrupole coupling tensor. If this tensor is transformed to its principal axes the coupling constants of the four deuterium atoms will be comparable. It seems reasonable to assume that the quadrupole tensor is approximately symmetric about the O-D bond. If this is the case it will have a coupling constant, $\chi$, associated with the bond axis and two non-unique coupling constants, $-\chi / 2$, perpendicular to the bond. The value of $\chi$ can then be found by substituting the ab initio predicted angle between the O-D bond and the a-principal inertial axis into the equation [28]

$$
\chi_{a a}=\chi\left(\frac{3 \cos ^{2} \theta-1}{2}\right)
$$


where $\theta$ is the angle between the O-D bond and the a-inertial axis. The angles relating the four O-D bonds to this inertial axis and the derived values of $\chi$ are displayed in table 10 .

The lowest energy homo and heterochiral conformers of butan-2,3-diol are so similar in structure that one would hope to obtain similar values of $\chi$ for the two deuterium environments in both species. For the deuterium in the proton accepting hydroxyl group this occurs and the two values of $\chi$ differ by only $3 \mathrm{kHz}$. In the donor deuterium environment this is not the case. An anomalous value occurs for the GtCM donor environment because the angle between the O-D bond and the a-inertial axis is close to $54.7^{\circ}$. At this angle the term $\left(3 \cos ^{2} \theta_{a z}-1\right)$ in equation is near to zero and hence the inertial axis quadrupole coupling terms, deduced from the spectrum are poorly determined. The other three values of $\chi$ are similar to that of the deuterium quadrupole coupling in the trans OD rotamer of isopropanol, reported by Hirota and Kawashima [29], who found that $\chi$ is equal to $269.3 \mathrm{kHz}$.

A comparison of the two proton environments in the hydrogen bond is limited to the heterochiral conformer, because of the anomalous value of $\chi$ that occurs for the GtCM donor environment. The values of the principal quadrupole coupling constant for the heterochiral species suggest that the difference in $\chi$ produced by the two deuteron environments is close to $50 \mathrm{kHz}$.

\subsection{The tunnelling path of the GtCM conformer}

There are four possible combinations of $120^{\circ}$ and $240^{\circ}$ rotations of the hydroxyl groups that will interconvert the two equivalent minima of the GtCM/GtMC conformer. These paths are illustrated in figure 7 . Intuitively the path that involves a $120^{\circ}$ rotation of both hydroxyl groups appears to be the most favourable as it requires both hydroxyl hydrogens to pass over C-H bonds, rather than C-C bonds. 
This guess at the most likely tunnelling path is supported by the microwave work of Christen et al., which has shown that the $\mathrm{g}^{\prime} \mathrm{Ga}$ conformer of ethylene glycol undergoes a concerted $120^{\circ}, 120^{\circ}$ tunnelling path, at a frequency of $7 \mathrm{GHz}$ [13]. The decrease in the tunnelling splitting between the two systems is assumed to indicate that the positions of the methyl groups in butan-2,3-diol must change slightly during the tunnelling process. This will increase the reduced mass involved in the tunnelling motion and decrease the tunnelling splitting.

\section{Concluding remarks}

The assignment of the two observed conformers of butan-2,3-diol to the conformational ground states of the homo and heterochiral species is supported by the Kraitchman analyses and the tunnelling properties of the homochiral species. These species have also accounted for all of the most intense observed transitions, as would be expected if they are indeed the most populated conformational states. The microwave spectrum of butan2,3-diol is, however, very dense and many weaker lines, which could arise from excited conformational states, uncommon isotopomers, rare gas-butan-2,3-diol complexes, dimers and higher clusters, are still unassigned.

\section{Acknowledgements}

The support of the EPSRC is gratefully acknowledged. We also thank Professor D. Christen for helpful discussions.

\section{References}

[1] L. P. Kuhn, J. Am. Chem. Soc., 80, 5950 (1958). 
[2] E. L. Eliel and S. H. Wilen, Stereochemistry of Organic Compounds, John Wiley \& Sons Inc., New York (1994).

[3] J. Grochowski, B. Rhys, P. Serda and U. Wagner, Tetrahedron: Asymmetry, 6, 2059 (1995).

[4] S. G. Davies, R. F. Newton and J. M. J. Williams, Tetrahedron Lett., 30, 2967 (1989).

[5] L. Angiolini, C. Carlini and E. Salatelli, Makromol. Chem., 193, 2883 (1992).

[6] K. Awano, T. Yanai, I. Watanabe, Y. Tagaki, T. Kitahara and K. Mori, Biosci. Biotechnol. Biochem., 59, 1251, (1995).

[7] A. Szarecka, M. Hoffmann, J. Rychlewski and U. J. Rychlewska, J. Mol. Struct., 374, 363 (1996).

[8] F. Wang and P. L. Polavarapu, J. Phys. Chem A, 105, 6991 (2001).

[9] W. Caminati and G. Corbelli, J. Mol. Spectrosc., 90, 572 (1981).

[10] P. E. Kristiansen, K. M. Marstokk and H. Møllendal, Acta Chem. Scand. A, 41, 403 (1987)

[11] K. M. Marstokk and H. Møllendal, J. Mol. Struct., 22, 301 (1974).

[12] E. Walder, A. Bauder and Hs. H. Günthard, Chem. Phys., 51, 223 (1980).

[13] D. Christen, L. H. Coudert, R. D. Suenram and F. J. Lovas, J. Mol. Spectrosc., 172, 57 (1995).

[14] D. Christen, L. H. Coudert, J. A. Larsson and D. Cremer, J. Mol. Spectrosc., 205, 185 (2001).

[15] D. Christen and H.S.P. Muller, PCCP, 5, 3600 (2003).

[16] H.S.P. Muller and D. Christen, J. Mol. Spectrosc. 5, 298 (2004).

[17] W. Caminati, J. Mol. Spectrosc., 86, 193 (1981).

[18] T. J. L. Lockley, J. P. I. Hearn, A. K. King and B. J. Howard, J. Mol. Struct., 612, 199 (2002). 
[19] Gaussian 98, Revision A.3, M. J. Frisch, G. W. Trucks, H. B. Schlegel et al. Gaussian, Inc., Pittsburgh PA, (1998).

[20] C.J. Whitham, R.J. Low and B.J. Howard, Chem. Phys. Lett. 286, 408 (1998).

[21] J.K.G. Watson Vibrational Spectra and Structure, Vol 6, Ed J.R. Durig (Elsevier) p.1 (1977).

[22] J. Kraitchman, Am. J. Phys., 21, 17 (1953).

[23] J. T. Hougen, J. Mol. Spectrosc., 114, 395 (1985).

[24] L. H. Coudert and J. T. Hougen, J. Mol. Spectrosc., 130, 86 (1988).

[25] H. M. Pickett, J. Chem. Phys., 56, 1715 (1972).

[26] H. M. Pickett, J. Mol. Spectrosc., 148, 371 (1991).

[27] H. W. Kroto, Molecular Rotation Spectra, (John Wiley \& Sons, London, 1975).

[28] W. Gordy and R. L. Cook, Microwave Molecular Spectra, (John Wiley \& Sons, New York, 1970).

[29] E. Hirota and Y. Kawashima, J. Mol. Spectrosc., 207, 243 (2001). 
Table 1: The energies of the conformers of $(R, S)$-butan-2,3-diol geometry optimized at the HF/6-311G level.

\begin{tabular}{|c|c|c|c|}
\hline Conformer & $E / E_{\mathrm{h}}$ & $E_{\mathrm{rel}} / \mathrm{cm}^{-1}$ & $\mathrm{H}$ bond \\
\hline $\mathrm{G}_{\mathrm{l}} \mathrm{CM} \equiv \mathrm{G}_{\mathrm{r}} \mathrm{MC}$ & -306.8810923 & 0 & Yes \\
\hline $\mathrm{G}_{1} \mathrm{CC} \equiv \mathrm{G}_{\mathrm{r}} \mathrm{CC}$ & \multicolumn{2}{|c|}{ Converted to $\mathrm{G}_{\mathrm{l}} \mathrm{CM} \equiv \mathrm{G}_{\mathrm{r}} \mathrm{MC}$} & No \\
\hline $\mathrm{G}_{1} \mathrm{HM} \equiv \mathrm{G}_{\mathrm{r}} \mathrm{MH}$ & \multicolumn{2}{|c|}{ Converted to $\mathrm{G}_{\mathrm{l}} \mathrm{CM} \equiv \mathrm{G}_{\mathrm{r}} \mathrm{MC}$} & No \\
\hline $\mathrm{G}_{1} \mathrm{HC} \equiv \mathrm{G}_{\mathrm{r}} \mathrm{CH}$ & -306.8797009 & 305 & Yes \\
\hline $\mathrm{G}_{1} \mathrm{MC} \equiv \mathrm{G}_{\mathrm{r}} \mathrm{CM}$ & \multicolumn{2}{|c|}{ Converted to $\mathrm{G}_{\mathrm{l}} \mathrm{HC} \equiv \mathrm{G}_{\mathrm{r}} \mathrm{CH}$} & No \\
\hline TCC & -306.8790738 & 443 & No \\
\hline $\mathrm{G}_{1} \mathrm{MM} \equiv \mathrm{G}_{\mathrm{r}} \mathrm{MM}$ & -306.8790667 & 445 & Yes \\
\hline $\mathrm{G}_{1} \mathrm{MH} \equiv \mathrm{G}_{\mathrm{r}} \mathrm{HM}$ & \multicolumn{2}{|c|}{ Converted to $\mathrm{G}_{\mathrm{l}} \mathrm{HH} \equiv \mathrm{G}_{\mathrm{r}} \mathrm{HH}$} & No \\
\hline $\mathrm{G}_{\mathrm{l}} \mathrm{HH} \equiv \mathrm{G}_{\mathrm{r}} \mathrm{HH}$ & -306.8776857 & 748 & Yes \\
\hline $\mathrm{THC} \equiv \mathrm{TCH}$ & -306.8773939 & 812 & No \\
\hline $\mathrm{TMC} \equiv \mathrm{TCM}$ & -306.8773328 & 825 & No \\
\hline TMM & -306.8767426 & 955 & No \\
\hline THH & -306.8760264 & 1112 & No \\
\hline $\mathrm{THM} \equiv \mathrm{TMH}$ & -306.8752805 & 1276 & No \\
\hline $\mathrm{G}_{1} \mathrm{CH} \equiv \mathrm{G}_{\mathrm{r}} \mathrm{HC}$ & -306.8701875 & 2393 & No \\
\hline
\end{tabular}


Table 2: The properties of the lowest energy conformers of $(R, S)$-butan-2,3-diol optimized at MP2/6-311++G**.

\begin{tabular}{c|cccccccc} 
Conformer & $A / \mathrm{MHz}$ & $B / \mathrm{MHz}$ & $C / \mathrm{MHz}$ & $\mu_{\mathrm{a}} / \mathrm{D}$ & $\mu_{b} / \mathrm{D}$ & $\mu_{c} / \mathrm{D}$ & $E / E_{\mathrm{h}}$ & $\begin{array}{c}E_{\mathrm{rel}} / \\
\mathrm{cm}^{-1}\end{array}$ \\
\hline $\mathrm{G}_{\mathrm{l}} \mathrm{CM} \equiv \mathrm{G}_{\mathrm{r}} \mathrm{MC}$ & 4665.9 & 2871.9 & 2350.2 & 1.7 & 1.9 & 1.0 & -308.1263317 & 0 \\
$\mathrm{G}_{1} \mathrm{HC} \equiv \mathrm{G}_{\mathrm{r}} \mathrm{CH}$ & 4607.4 & 2843.9 & 2360.0 & 2.9 & 0.4 & 0.0 & -308.1249394 & 306 \\
$\mathrm{G}_{\mathrm{l}} \mathrm{MM} \equiv \mathrm{G}_{\mathrm{r}} \mathrm{MM}$ & 4669.1 & 2830.7 & 2344.8 & 0.2 & 0.5 & 2.5 & -308.125464 & 190 \\
$\mathrm{G}_{1} \mathrm{HH} \equiv \mathrm{G}_{\mathrm{r}} \mathrm{HH}$ & 4557.6 & 2852.7 & 2331.7 & 1.9 & 2.2 & 0.9 & -308.1241772 & 473 \\
$\mathrm{TCC}$ & 4572.7 & 3107.8 & 1999.6 & 0.0 & 0.0 & 0.0 & -308.1232344 & 680
\end{tabular}


Table 3: The energies of the conformers of $(S, S)$ and $(R, R)$-butan-2,3-diol geometry optimized at the HF/6-311G level.

\begin{tabular}{|c|c|c|c|}
\hline Conformer & $E / E_{\mathrm{H}}$ & $E_{\mathrm{rel}} / \mathrm{cm}^{-1}$ & $\mathrm{H}$ bond \\
\hline $\mathrm{GtCM}$ & -306.8815422 & 0 & Yes \\
\hline $\mathrm{GtHC}$ & \multicolumn{2}{|c|}{ Converted to GtCM } & No \\
\hline THC & -306.8807831 & 167 & Yes \\
\hline GtMH & -306.8794134 & 467 & Yes \\
\hline THM & -306.8788301 & 595 & Yes \\
\hline $\mathrm{GtCC}$ & \multicolumn{2}{|c|}{ Converted to GtMM } & No \\
\hline GtMM & -306.8786928 & 625 & No \\
\hline $\mathrm{GgCC}$ & -306.877986 & 780 & No \\
\hline THH & -306.8778043 & 820 & No \\
\hline TCC & \multicolumn{2}{|c|}{ Converted to $\mathrm{THH}$} & No \\
\hline GgMC & -306.876508 & 1105 & No \\
\hline $\mathrm{GgHC}$ & -306.8759726 & 1222 & No \\
\hline GgHM & -306.8753539 & 1358 & No \\
\hline GgMM & -306.8750526 & 1424 & No \\
\hline TMM & -306.737299 & 1715 & No \\
\hline GtHH & -306.736728 & 1727 & No \\
\hline $\mathrm{GgHH}$ & -306.733768 & 1792 & No \\
\hline TMC & -306.713747 & 2231 & No \\
\hline
\end{tabular}


Table 4: The properties of the lowest energy conformers of $(S, S)$ and $(R, R)$-butan-2,3-diol optimized at MP2 / 6-311++G**.

\begin{tabular}{c|ccccccccc} 
Conformer & $A / \mathrm{MHz}$ & $B / \mathrm{MHz}$ & $C / \mathrm{MHz}$ & $\mu_{\mathrm{a}} / \mathrm{D}$ & $\mu_{b} / \mathrm{D}$ & $\mu_{c} / \mathrm{D}$ & $E / E_{\mathrm{h}}$ & $\begin{array}{c}E_{\text {rel }} / \\
\mathrm{cm}^{-1}\end{array}$ \\
\hline GtCM & 4578.7 & 3090.9 & 1994.6 & 2.5 & 1.6 & 0.7 & -308.126606 & 0 \\
GtMH & 4571.1 & 3061.2 & 1987.8 & 1.6 & 2.0 & 1.4 & -308.1260706 & 117 \\
THC & 4773.1 & 2765.2 & 2414.4 & 1.9 & 1.4 & 1.3 & -308.1255081 & 240 \\
THM & 4763.2 & 2739.6 & 2399.1 & 0.5 & 2.0 & 0.7 & -308.1243612 & 492 \\
GtMM & 4612.6 & 3007.5 & 1985.0 & 0.0 & 0.7 & 0.0 & -308.1241789 & 533
\end{tabular}


Table 5: Spectral parameters of the $\mathrm{G}_{1} \mathrm{CM} / \mathrm{G}_{\mathrm{r}} \mathrm{CM}$ conformer of heterochiral butan-2,3-diol.

\begin{tabular}{|c|c|c|c|}
\hline & Parent & Proton Donor & Proton Acceptor \\
& Isotopomer & Group Deuterated & Group Deuterated \\
\hline
\end{tabular}

\begin{tabular}{|c|c|c|c|}
\hline$A / \mathrm{MHz}$ & $4640.0465(2)$ & $4497.4826(8)$ & $4629.2594(8)$ \\
\hline$B / \mathrm{MHz}$ & $2840.8899(2)$ & $2832.7649(7)$ & $2745.8061(9)$ \\
\hline$C / \mathrm{MHz}$ & $2343.3848(2)$ & $2312.9114(7)$ & $2278.3988(8)$ \\
\hline
\end{tabular}

\begin{tabular}{|c|c|c|c|}
\hline$\Delta_{J} / \mathrm{kHz}$ & $0.932(9)$ & $0.993(23)$ & $0.850(30)$ \\
\hline$\Delta_{J K} / \mathrm{kHz}$ & $-1.165(5)$ & $-1.06(9)$ & $-0.94(13)$ \\
\hline$\Delta_{K} / \mathrm{kHz}$ & $1.616(11)$ & $0.63(20)$ & $1.47(19)$ \\
\hline$\delta_{J} / \mathrm{kHz}$ & $0.240(6)$ & $0.251(13)$ & $0.316(22)$ \\
\hline$\delta_{K} / \mathrm{kHz}$ & $3.481(11)$ & $3.10(24)$ & $2.95(36)$ \\
\hline
\end{tabular}

\begin{tabular}{|c|c|c|c|}
\hline$\chi_{a a} / \mathrm{kHz}$ & - & $117.1(14)$ & $219.5(15)$ \\
\hline$\left(\chi_{b b}-\chi_{c c}\right) / \mathrm{kHz}$ & - & $100.4(40)$ & $43.5(38)$ \\
\hline
\end{tabular}

\begin{tabular}{|c|c|c|c|}
\hline$N^{a}$ & 52 & 56 & 47 \\
\hline$\sigma_{r m s} / \mathrm{kHz}$ & 1.7 & 4.3 & 3.1 \\
\hline
\end{tabular}

${ }^{\mathrm{a}}$ The total number of lines included in the fit. 
Table 6: Spectral parameters of the deuterohydroxyl isotopomers of the GtCM conformer of homochiral butan-2,3-diol.

\begin{tabular}{|c|c|c|}
\hline & $\begin{array}{c}\text { Proton Donor Group } \\
\text { Deuterated }\end{array}$ & $\begin{array}{c}\text { Proton Acceptor Group } \\
\text { Deuterated }\end{array}$ \\
\hline & & \\
\hline$A / \mathrm{MHz}$ & $4437.9005(9)$ & $4505.6211(13)$ \\
\hline$B / \mathrm{MHz}$ & $3061.3386(10)$ & $2987.7452(7)$ \\
\hline $\mathrm{C} / \mathrm{MHz}$ & $1956.2602(4)$ & $1940.6420(7)$ \\
\hline
\end{tabular}

\begin{tabular}{|c|c|c|}
\hline$\Delta_{J} / \mathrm{kHz}$ & $0.455(20)$ & $0.442(28)$ \\
\hline$\Delta_{J K} / \mathrm{kHz}$ & -0.580 & $-0.56(11)$ \\
\hline$\Delta_{K} / \mathrm{kHz}$ & $1.41(25)$ & $1.3(8)$ \\
\hline$\delta_{J} / \mathrm{kHz}$ & $0.170(17)$ & $0.18(2)$ \\
\hline$\delta_{K} / \mathrm{kHz}$ & $0.361^{\mathrm{a}}$ & $0.361^{\mathrm{a}}$ \\
\hline
\end{tabular}

\begin{tabular}{|c|c|c|}
\hline$\chi_{a a} / \mathrm{kHz}$ & $16.9(34)$ & $166.9(19)$ \\
\hline$\left(\chi_{b b}-\chi_{c c}\right) / \mathrm{kHz}$ & $275.8(34)$ & $-80.0(52)$ \\
\hline
\end{tabular}

\begin{tabular}{|c|c|c|}
\hline$N$ & 26 & 26 \\
\hline$\sigma_{\text {rms }} / \mathrm{kHz}$ & 2.6 & 1.9 \\
\hline
\end{tabular}

\footnotetext{
${ }^{\mathrm{a}}$ Constrained to the value for the parent isotopomer (table 4.7).
} 
Table 7: Spectral parameters of the GtCM conformer of homochiral butan-2,3-diol.

\begin{tabular}{|c|c|c|}
\hline & Full Fit & Fit of b-type cycles \\
\hline$A / \mathrm{MHz}$ & $4574.8694(2)$ & $4574.8330(11)$ \\
\hline$B / \mathrm{MHz}$ & $3072.5964(2)$ & $3072.5832(3)$ \\
\hline$C / \mathrm{MHz}$ & $1987.0638(2)$ & $1987.0550(3)$ \\
\hline
\end{tabular}

\begin{tabular}{|c|c|c|}
\hline$\Delta A / \mathrm{kHz}$ & $12.46(8)$ & $23.6(9)$ \\
\hline$\Delta B / \mathrm{kHz}$ & $14.62(4)$ & $26.1(4)$ \\
\hline$\Delta C / \mathrm{kHz}$ & $4.28(6)$ & $2.5(3)$ \\
\hline
\end{tabular}

\begin{tabular}{|c|c|c|}
\hline$\Delta_{J} / \mathrm{kHz}$ & $0.468(6)$ & - \\
\hline$\Delta_{J K} / \mathrm{kHz}$ & $-0.580(8)$ & - \\
\hline$\Delta_{K} / \mathrm{kHz}$ & $1.446(7)$ & - \\
\hline$\delta_{J} / \mathrm{kHz}$ & $0.1672(14)$ & - \\
\hline$\delta_{K} / \mathrm{kHz}$ & $0.361(7)$ & \\
\hline
\end{tabular}

\begin{tabular}{|c|c|c|}
\hline$\Delta_{\text {tun }} / \mathrm{MHz}$ & $1011.9781(6)$ & $1024.4(7)$ \\
\hline$F_{a b} / \mathrm{MHz}$ & $10.9472(13)$ & $11.444(18)$ \\
\hline$F_{b c} / \mathrm{MHz}$ & $8.3800(4)$ & $8.356(14)$ \\
\hline
\end{tabular}

\begin{tabular}{|c|c|c|}
\hline$N$ & 96 & 16 \\
\hline$\sigma_{r m s} / \mathrm{kHz}$ & 0.67 & 9.6 \\
\hline
\end{tabular}


Table 8: Principal axis coordinates of the hydroxyl hydrogen atoms in the conformers of heterochiral butan-2,3-diol from isotopic substitution and ab initio calculations.

\begin{tabular}{|c|c|c|c|c|c|c|}
\hline & \multicolumn{3}{|c|}{ Donor OH hydrogen } & \multicolumn{3}{c|}{ Acceptor OH hydrogen } \\
\hline & $a / \AA$ & $b / \AA$ & $c / \AA$ & $a / \AA$ & $b / \AA$ & $c / \AA$ \\
\hline Exp. & $0^{\mathrm{a}}$ & \pm 1.710 & \pm 0.753 & \pm 2.469 & \pm 0.352 & \pm 0.365 \\
\hline $\mathrm{G}_{\mathrm{l}} \mathrm{CM} \equiv \mathrm{G}_{\mathrm{r}} \mathrm{MC}$ & -0.053 & -1.659 & 0.817 & 2.469 & -0.415 & -0.243 \\
\hline $\mathrm{G}_{\mathrm{l}} \mathrm{HC} \equiv \mathrm{G}_{\mathrm{r}} \mathrm{CH}$ & 1.424 & -1.310 & 0.232 & -1.515 & -1.606 & 0.87 \\
\hline $\mathrm{G}_{\mathrm{l}} \mathrm{MM} \equiv \mathrm{G}_{\mathrm{r}} \mathrm{MM}$ & -0.019 & -1.583 & 0.886 & 1.619 & -1.206 & -1.169 \\
\hline $\mathrm{G}_{\mathrm{l}} \mathrm{HH} \equiv \mathrm{G}_{\mathrm{r}} \mathrm{HH}$ & 1.352 & -1.352 & 0.230 & -0.998 & -0.630 & 1.518 \\
\hline
\end{tabular}

Table 9: Principal axis coordinates of the hydroxyl hydrogen atoms in the conformers of homochiral butan-2,3-diol from isotopic substitution and $a b$ initio calculations.

\begin{tabular}{|c|c|c|c|c|c|c|}
\hline & \multicolumn{3}{|c|}{ Donor OH hydrogen } & \multicolumn{3}{c|}{ Acceptor OH hydrogen } \\
\hline & $a / \AA$ & $b / \AA$ & $c / \AA$ & $a / \AA$ & $b / \AA$ & $c / \AA$ \\
\hline Exp. & \pm 0.779 & \pm 1.856 & \pm 0.069 & \pm 2.140 & \pm 1.254 & \pm 0.380 \\
\hline GtCM & 0.760 & -1.857 & -0.023 & -2.121 & -1.287 & 0.393 \\
\hline GtMH & -0.720 & -1.853 & -0.032 & 1.678 & -1.083 & 0.916 \\
\hline THC & 0.595 & -0.589 & 1.503 & -1.631 & 1.395 & 0.923 \\
\hline
\end{tabular}


Table 10: Calculated axial deuterium quadrupole coupling constants of the conformers of butan-2,3-diol.

\begin{tabular}{|c|c|c|c|c|}
\hline & \multicolumn{2}{|c|}{$\mathrm{G}_{\mathrm{l}} \mathrm{CM} / \mathrm{G}_{\mathrm{r}} \mathrm{MC}$} & \multicolumn{2}{c|}{ GtCM } \\
\hline & Donor & Acceptor & Donor & Acceptor \\
\hline$\theta$ & $35.8^{\circ}$ & $23.7^{\circ}$ & $49.2^{\circ}$ & $31.8^{\circ}$ \\
\hline$\chi / \mathrm{kHz}$ & 240 & 290 & 121 & 287 \\
\hline
\end{tabular}




\section{Figure captions.}

Figure 1. The hydrogen bonded conformations of meso and racemic butan-2,3-diol.

Figure 2. A nomenclature for the conformations of butan-2,3-diol.

Figure 3. The lowest energy structural minima of the heterochiral butan-2,3-diol (together with relative MP2/6-311++G** energies).

Figure 4. The three lowest energy structural minima of homochiral butan-2,3-diol (together with relative MP2/6-311++G** energies).

Figure 5. The tunnelling motion and approximate principal inertial axes of the GtCM conformer of butan-2,3-diol.

Figure 6. The b-type cycles of upper and lower tunnelling states of the GtCM conformer of butan-2,3-diol.

Figure 7. The four likely tunnelling paths of the GtCM conformer of butan-2,3-ol.

Figure 1. The hydrogen bonded conformations of meso and racemic butan-2,3-diol.

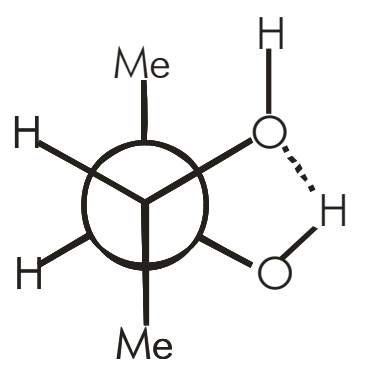

$\operatorname{Racemic}(R, R$ and $S, S)$<smiles>CC1C2COC3(OCOC13)C2C</smiles>

$\operatorname{Meso}(R, S$ and $S, R)$ 
Figure 2. A nomenclature for the conformations of butan-2,3-diol.

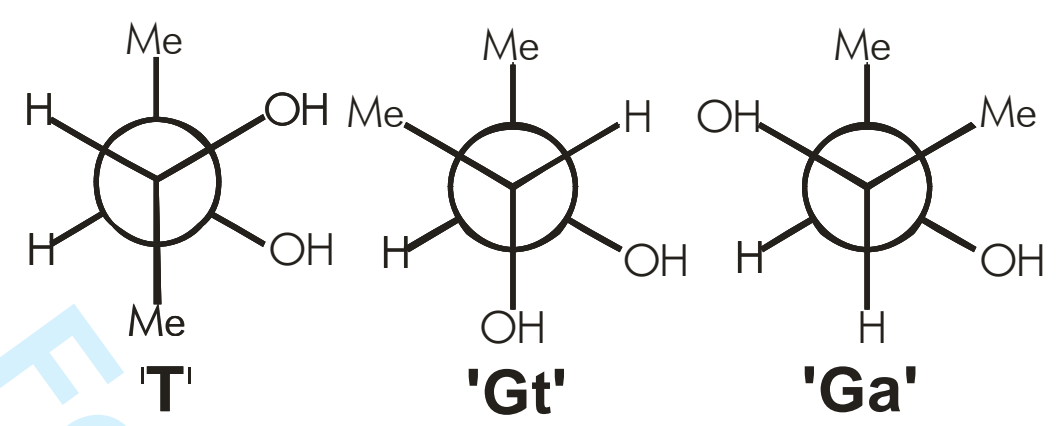<smiles>CC1C2CC3(C)C(O)C1C(C2O)C3O</smiles><smiles>CC1C(O)C2CCC1C(O)C2C</smiles><smiles>CC1C(C)C2CC(C1O)C(O)C2C</smiles>

'T

'G'

'G'<smiles>Cc1cc(C(=O)O)ccc1[14CH3]</smiles><smiles>Cc1ccc(C=O)c(C(=O)O)c1</smiles><smiles>Cc1cccc(O)c1O</smiles> 
Figure 3. The lowest energy structural minima of the heterochiral butan-2,3-diol (together with relative MP2/6-311++G** energies).

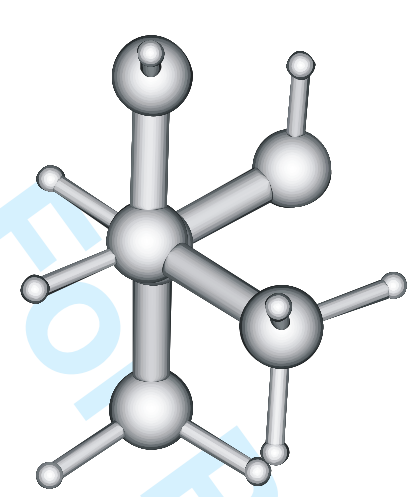

$\mathrm{G}_{1} \mathrm{CM} / \mathrm{G}_{\mathrm{r}} \mathrm{MC}$

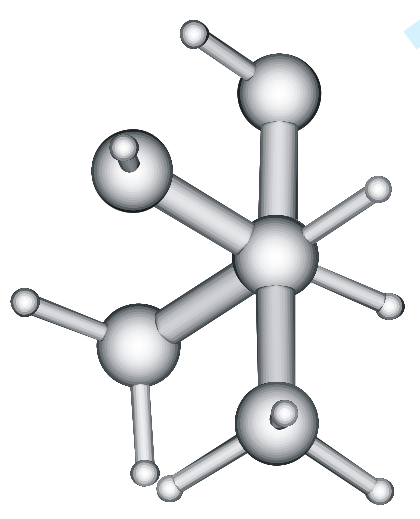

$\mathrm{G}_{1} \mathrm{HC} / \mathrm{G}_{\mathrm{H}} \mathrm{CH}$
$+306 \mathrm{~cm}^{-1}$

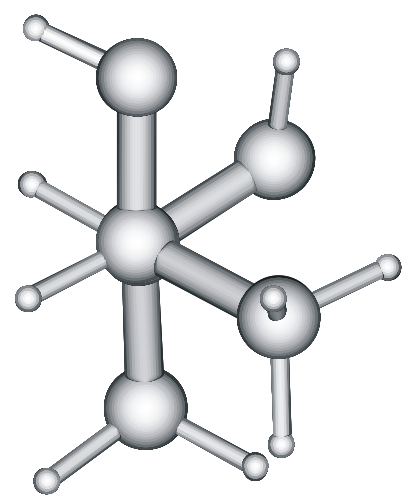

$\mathrm{G}_{\mathrm{P}} \mathrm{MM} / \mathrm{G}_{\mathrm{r}} \mathrm{MM}$

$+190 \mathrm{~cm}^{-1}$

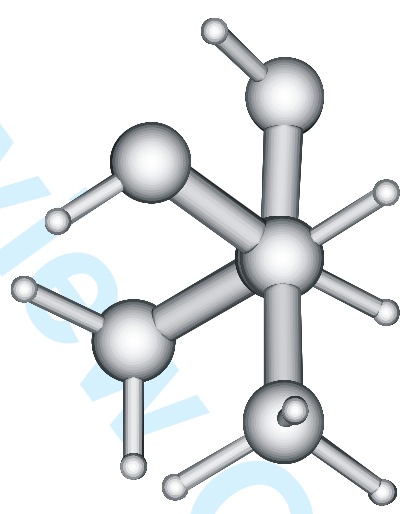

$\mathrm{G}_{1} \mathrm{HH} / \mathrm{G}_{\mathrm{r}} \mathrm{HH}$

$+473 \mathrm{~cm}^{-1}$ 
Figure 4. The three lowest energy structural minima of homochiral butan-2,3-diol (together with relative MP2/6-311++G** energies).

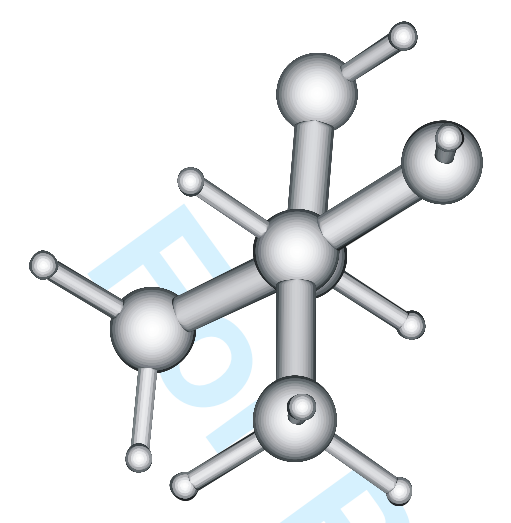

GtCM

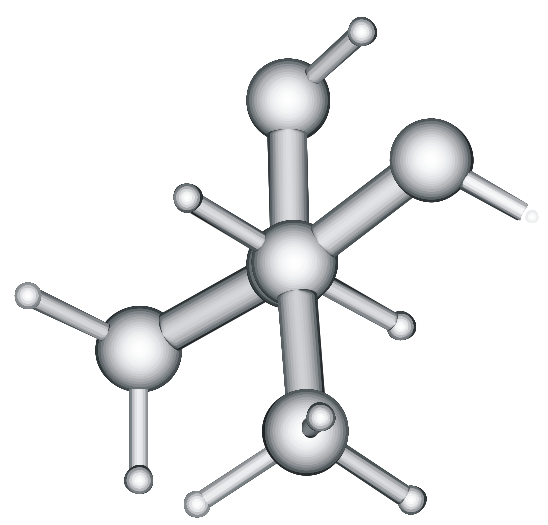

GtMH

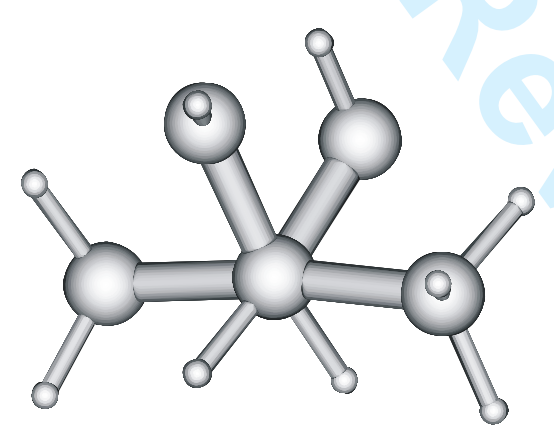

$\mathrm{THC} / \mathrm{TCH}$

$$
+240 \mathrm{~cm}^{-1}
$$


Figure 5. The tunnelling motion and approximate principal inertial axes of the GtCM conformer of butan-2,3-diol.

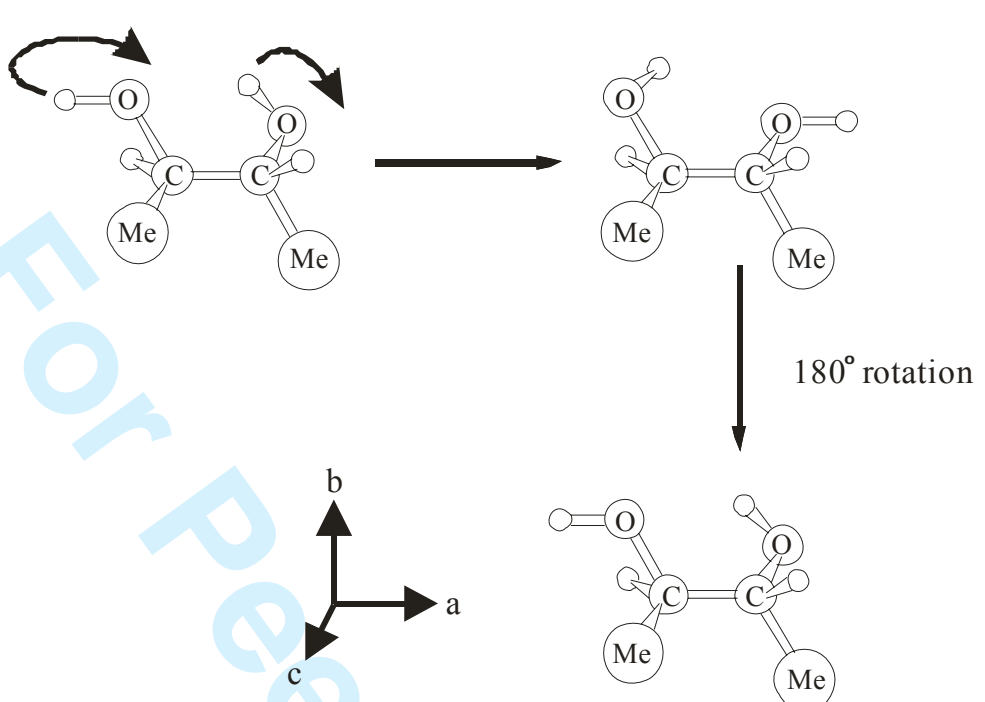

28 
Figure 6. The b-type cycles of upper and lower tunnelling states of the GtCM conformer of butan-2,3-diol.

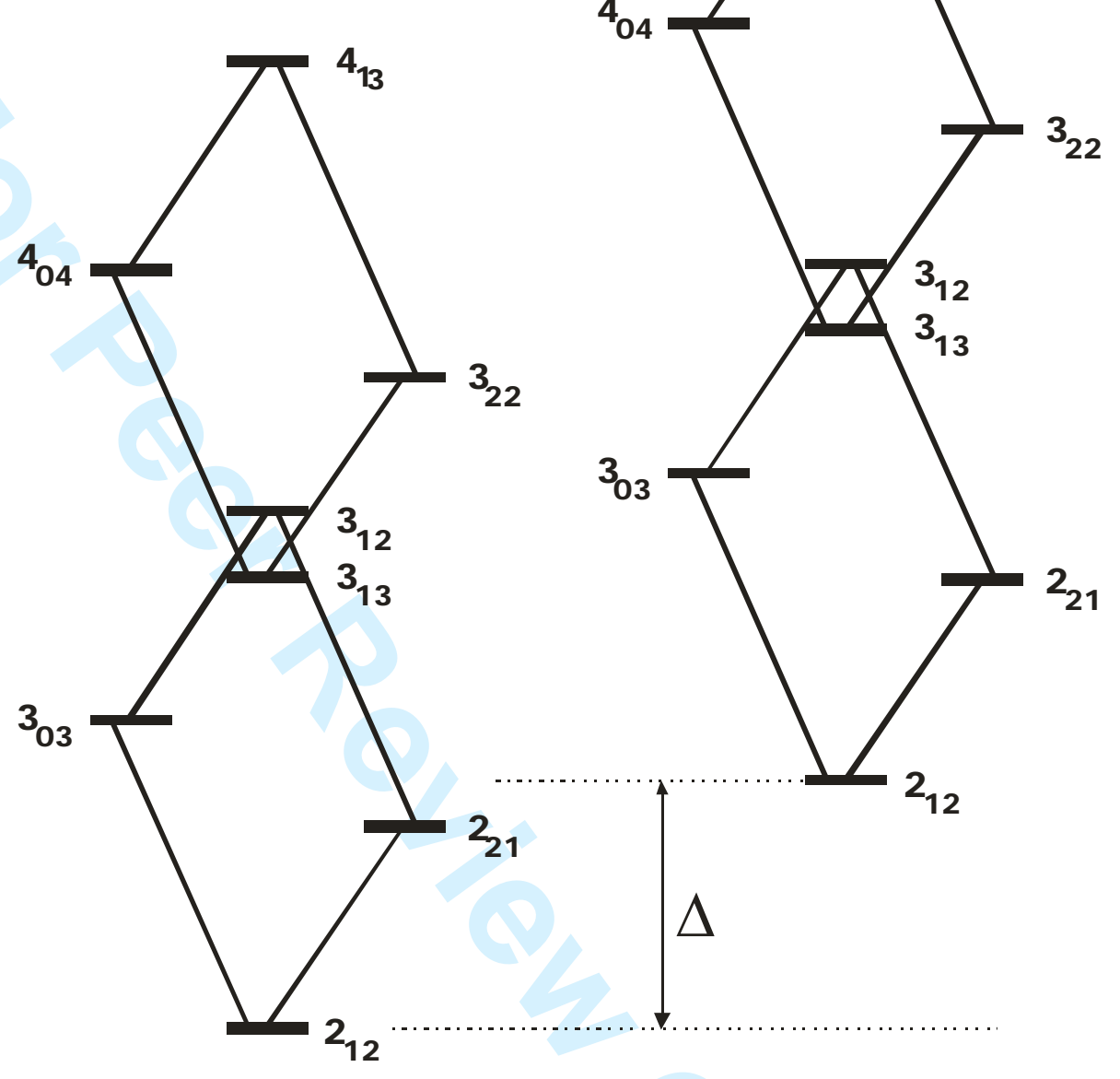


Figure 7. The four likely tunnelling paths of the GtCM conformer of butan-2,3-ol.

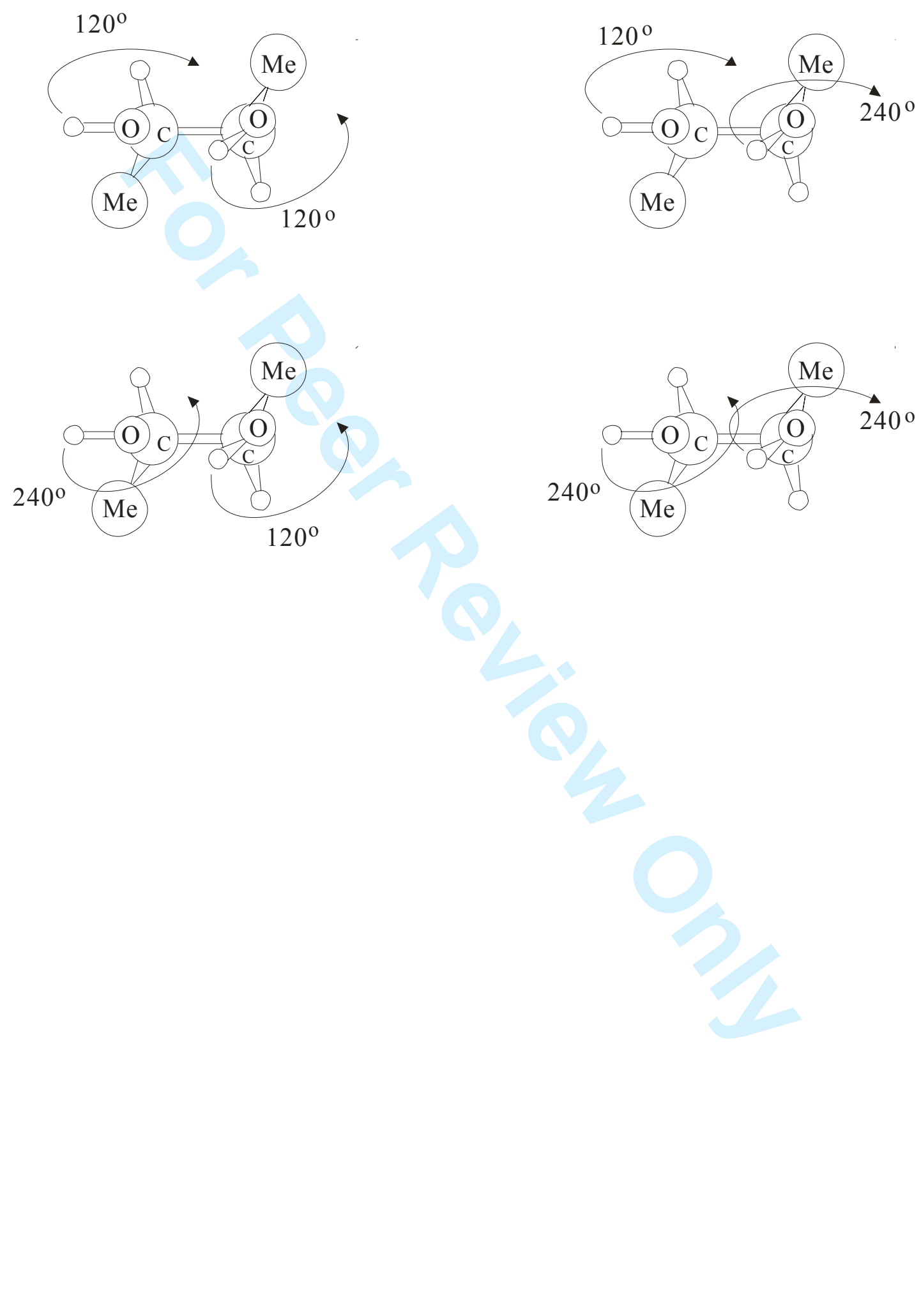


1

2

3

4

5

6

7

8

Chiral recognition in a single molecule: A study of homo and heterochiral

butan-2,3-diol by Fourier transform microwave spectroscopy.

\section{J. Paul I. Hearn and Brian J. Howard.}

Physical and Theoretical Chemistry Laboratory

Department of Chemistry

Oxford University

South Parks Road

Oxford, OX1 3QZ

United Kingdom

Author for correspondence :

Professor Brian. J. Howard

Physical and Theoretical Chemistry Laboratory

South Parks Road

Oxford, OX1 3QZ

United Kingdom

Telephone : +44 1865275438

Fax : +441865 275410

E-mail: brian.howard@chem.ox.ac.uk

Running title: microwave spectroscopy of butandiol 


\begin{abstract}
The microwave Fourier transform spectrum of butan-2,3-ol has been recorded in the range 5$18 \mathrm{GHz}$. The molecule possesses two chiral centres and exists in two distinct forms, one of which is homochiral $((R, R)$ or $(S, S))$ and is overall chiral, and the other which is heterochiral $((R, S)$ or $(S, R))$ and is overall meso. Detailed ab initio calculations enabled investigation of the relative stability of the many conformations exhibited by each form of the molecule. It is shown that the lowest energy forms in each case possess an internal hydrogen bond. The spectrum of the heterochiral (meso) form could be readily identified and analysed. The homochiral form, however, exhibits a tunnelling motion of about $1 \mathrm{GHz}$, in which the hydrogen bonded OH groups interchange their roles. Deuteration of one of these OH protons quenches the tunnelling motion, aiding the assignment of the spectrum. In all cases, deuteration of the hydroxyl groups was used to locate the positions of the $\mathrm{OH}$ hydrogen atoms and helped to confirm the identification of the conformers present.
\end{abstract}




\section{Introduction}

Butan-2,3-diol, is a fascinating molecule. It possesses two chiral centres and hence, exists as two pairs of enantiomers. These enantiomeric pairs differ only in their chirality, but should have very different properties. The lowest conformers in energy exhibit an intramolecular hydrogen bond, which should pronounce the chiral recognition effect in the molecule. Most interesting of all, however, the chiral recognition will affect the dynamic properties, as well as the rigid structure, because of the symmetries of the different isomers.

A considerable volume of work has been carried out on butan-2,3-diol. The conformations of chiral $(R, R$ and $S, S)$ and meso-butan-2,3-diol $(R, S)$ in $\mathrm{CCl}_{4}$ were compared by Kuhn $[1,2]$ via infrared spectroscopy. He concluded that the ratio of hydrogen bonded and non-hydrogen bonded $\mathrm{OH}$ was larger for the chiral species. This has been explained in terms of the steric interaction of the methyl groups. The chiral species can form an intramolecular hydrogen bond when the two methyl groups are trans to one another, but the hydroxyl groups in the meso species may only interact in this way when the methyl groups are forced into a gauche conformation (see figure 1). Kuhn also deduced that a stronger hydrogen bond was present in the chiral molecule by comparing the splittings between the free and bonded $\mathrm{OH}$ peaks.

Beyond the desire to study hydrogen bonding and chiral recognition, the stereochemistry of many molecules have been related to $(2 R, 3 R)$-butan-2,3-diol and its derivatives [3-6]. The conformational properties of this isomer are also of interest as it has been used as a model for investigations of the methyl ester of $(R, R)$-tartaric acid monoamide [7]. An investigation by Wang et al. [8] utilized infrared spectroscopy and ab initio molecular orbital calculations to probe the conformational properties of this isomer in the solution phase. These authors found that the gauche hydrogen bonded conformation of the chiral molecule was more stable than the trans conformer, in disagreement with the work of Kuhn $[1,2]$. 
There has been recent interest in the conformations of other glycol molecules. The microwave spectra of asymmetrically deuterated forms of ethylene glycol were first assigned by Caminati et al. in $1981[9,10]$, but attempts to assign the spectrum of the parent isotopomer concluded that the molecule exhibits a large amplitude motion, which produces a tunnelling splitting in the spectrum and complicates the analysis $[11,12]$. Recently, however, Christen et al. have recorded microwave spectra of two conformers of ethylene glycol [13-16]. They found that the tunnelling splittings in the observed conformers were approximately $7 \mathrm{GHz}$ and 1.4 GHz. Microwave spectra of two conformers of propan-1,2-diol were also studied by Caminati [17]. The spectra of these species were re-examined recently, and a third conformer was assigned, which was found to be the global minimum for the molecule [18].

This paper presents the first assignment of the microwave spectra of the ground state conformers of chiral and meso butan-2,3-diol. This work has been augmented with an ab initio study, which has been used to provide geometrical predictions and to help decide which spectra arise from which conformers.

\section{The structure of butan-2,3-diol}

The butan-2,3-diol molecule has conformational flexibility about three bonds; different conformers may be generated by rotations about the central, $\mathrm{C}_{2}-\mathrm{C}_{3}$, bond or either of the two $\mathrm{C}-\mathrm{O}$ bonds, so the molecule possesses $3^{3}=27$ conformers. In addition, the presence of two chiral centres gives rise to four forms of the molecule, namely the $(R, R),(S, S),(R, S)$ and $(S$, $R$ ) configurations. Microwave spectroscopy will distinguish only the homo and heterochiral forms of the molecule, so the $a b$ initio study reviewed below considers $27 \mathrm{x} 2$ species. Initial geometry optimizations were performed on these systems with the Gaussian 98 package [19] at the HF/6-311G level. The geometries of the conformers lying lowest in energy were then reoptimized at the MP2/6-311++G** level. 


\subsection{The heterochiral species}

The 27 conformers of $(R, S)$ and $(S, R)$-butan-2,3-diol have been classified with a nomenclature of the form $X Y Z$. The nomenclature used for both the hetero and homochiral species is illustrated in figure 2 .

" $X$ " represents the geometry of the carbon chain, and is assigned as follows; if the two methyl groups are trans to one another $X=\mathrm{T}$. If the two methyl groups are gauche to one another $X=\mathrm{G}_{\mathrm{r}}$ or $\mathrm{G}_{\mathrm{l}}$. These two gauche orientations of the carbon chain are mirror images of one another. If the methyl and hydroxyl groups trans to one another are in the vertical plane, the methyl group points downwards and the molecule is viewed from the end nearest this methyl group, the classification is $\mathrm{G}_{\mathrm{r}}$ if the methyl group and hydroxyl group gauche to one another are on the right hand side. If this positioning of the trans methyl and hydroxyl groups leaves the remaining methyl and hydroxyl groups on the left, the classification is $\mathrm{G}_{1}$.

" $Y$ " denotes the position of the hydroxyl group, which is trans to the methyl group on the other chiral carbon atom. If the carbon chain is in the T position the two hydroxyl groups are equivalent and the labels " $Y$ " and ' $Z$ ' are interchangeable. The classification then considers the position of the $\mathrm{O}-\mathrm{H}$ bond relative to the groups attached to the chiral carbon to which the hydroxyl group is bonded. $X=\mathrm{M}$ if the $\mathrm{O}-\mathrm{H}$ bond is trans to the methyl group, $\mathrm{C}$ if the $\mathrm{O}-\mathrm{H}$ bond is trans to the carbon chain or $\mathrm{H}$ if it is trans to the hydrogen atom.

" $Z$ ' is classified in the same way as " $Y$ ", but denotes the position of the remaining hydroxyl group, which is gauche to the methyl group on the other chiral carbon atom.

Of these twenty-seven conformers nineteen were minima on the HF/6-311G potential surface (see table 1). These nineteen minima comprised all nine conformations where the methyl groups were trans to one another and five of each of the two gauche conformations. The minima were grouped in eight pairs of mirror images; the five $\mathrm{G}_{\mathrm{r}} Y Z$ minima being mirror 
images of the five $\mathrm{G}_{\mathrm{l}} Z Y$ minima and the trans conformers also forming mirror pairs (THC $\equiv \mathrm{TCH}),(\mathrm{TMC} \equiv \mathrm{TCM})$ and $(\mathrm{TMH} \equiv \mathrm{THM})$. Only the TCC, TMM and THH conformers are unique.

As one would expect, the four mirror pairs of conformers that display an intramolecular hydrogen bond tend to be the lowest in energy. These species, and the TCC conformer, were chosen for re-optimization at the MP2/6-311++G** level, which yielded the rotational constants, relative energies and dipole moments displayed in table 2 . The only large change during the re-optimization was the drop in energy of the GMM conformer. This was due to a large change in the angular orientation of the hydroxyl groups, resulting presumably from the inclusion of polarization functions in the basis set.

\subsection{The homochiral species}

The 27 conformers of $(R, R)$ and $(S, S)$-butan-2,3-diol have been classified in a similar manner to that described above, for the heterochiral molecule. As for the heterochiral species, the nomenclature is of the form $X Y Z$.

" $X$ " represents the geometry of the carbon chain. If the two methyl groups are trans to one another $X=\mathrm{T}$. If the two methyl groups are gauche to one another $X=\mathrm{Gg}$ or Gt. These two gauche conformations of the carbon chain are non-equivalent and differ in that both methyl groups are either trans $(\mathrm{Gt})$ or gauche $(\mathrm{Gg})$ to both hydroxyl groups.

Since the two hydroxyl groups are both either gauche or trans to the two methyl groups, for a specific orientation about the central C-C bond, they are equivalent. Hence, there is no way to distinguish between them, and " $Y$ " and " $Z$ " are interchangeable. As for the heterochiral molecule, $Y$ or $\mathrm{Z}=\mathrm{M}$ if the $\mathrm{O}-\mathrm{H}$ bond is trans to the methyl group, $\mathrm{C}$ if the $\mathrm{O}-\mathrm{H}$ bond is trans to the carbon chain or $\mathrm{H}$ if it is trans to the hydrogen atom. 
Twenty-three of the twenty-seven starting structures are minima on the HF/6-311G potential surface (see table 3). The equivalence of the two hydroxyl groups means that nine of the twenty seven starting conformers are unique, and that there are nine identical pairs. For instance, for the $\mathrm{Gg}$ carbon chain rotamers, the GgMM, GgHH and $\mathrm{GgCC}$ conformers are unique and the $(\mathrm{GgMC} \equiv \mathrm{GgCM}),(\mathrm{GgMH} \equiv \mathrm{GgHM})$ and $(\mathrm{GgHC} \equiv \mathrm{GgCH})$ are the identical pairs. Of the twenty-three minima from the $a b$ initio calculations, there are 7 unique conformers and 8 identical pairs. As in the heterochiral molecule, all conformers of the carbon chain orientation in which hydrogen bonding cannot occur $(\mathrm{Gg})$, were minima. Of the T-type carbon chain conformers there were three pairs and two unique structures. Two of these pairs, the THC and THM rotamers, exhibit an intramolecular hydrogen bond. The remaining two minima and two pairs were Gt-type rotamers. Both pairs of Gt-type minima possess a hydrogen bond,and it was these conformers that were found to be the lowest in energy of all. The results of MP2 calculations are given in table 4. This is in agreement with the ab initio study of Wang et al. [8], but contradicts the arguments given in references 1 and 2.

It is interesting to consider the calculated energy differences between the hetero and homochiral forms of butan-2,3-diol. The GtCM homochiral conformer has an energy about 60 $\mathrm{cm}^{-1}$ lower than the $\mathrm{G}_{\mathrm{l}} \mathrm{CM}$ and $\mathrm{G}_{\mathrm{r}} \mathrm{MC}$ heterochiral conformers. It seems likely that this energy difference arises for steric reasons; the projections of the conformers in figures 3 and 4 show that the sum of the angles between the bulky groups about the central C-C bond is only $180^{\circ}$ in the four lowest heterochiral conformers, but is $270^{\circ}$ in the two lowest homochiral conformers. The projections also show that the hydrogen bond in the GtCM conformer may be shortened by an increase in the separation of the two methyl groups, but in the $\mathrm{G}_{\mathrm{l}} \mathrm{CM}$ and $\mathrm{G}_{\mathrm{r}} \mathrm{MC}$ conformers the methyl group separation must decrease to shorten the hydrogen bond. Thus we might expect to find a stronger hydrogen bond in the homochiral species. 


\section{Experimental details}

Microwave transitions of butan-2,3-diol were recorded with the Fourier transform spectrometer which has been described previously [20]. The sample was heated to about $70^{\circ} \mathrm{C}$, in order to produce an appropriate concentration of butan-2,3-diol and the nozzle to about $75^{\circ} \mathrm{C}$ to prevent blocking. Helium at 1.5 bar was used as the backing gas for all spectroscopic investigations.

Samples of meso $((R, S),(S, R))$ and racemic $((R, R),(S, S),(R, S),(S, R))$-butan-2,3diol were purchased from Sigma-Aldrich. A chiral sample of $(R, R)$-butan-2,3-diol was also acquired, from Acrōs Organics. The hydroxyl groups of the racemic sample were deuterated by distilling a mixture of $25 \mathrm{ml}$ of butan-2,3-diol and $10 \mathrm{ml}$ of $\mathrm{D}_{2} \mathrm{O}$. This procedure was only performed once, as the aim was to maximise the quantities of the mono-deutero-diols.

\subsection{Experimental results I: Heterochiral butan-2,3-diol}

The first spectra recorded were obtained by scanning over frequency ranges of about $200 \mathrm{MHz}$ around the predicted $0_{00}-1_{11}, 1_{01}-2_{12}, 2_{02}-3_{13}$ and $2_{11}-3_{03}$ transitions of the $\mathrm{G}_{1} \mathrm{CM} / \mathrm{G}_{\mathrm{r}} \mathrm{MC}$ conformers of $(R, S)$-butan-2,3-diol. Several strong transitions were found in each frequency range but rotational constants derived from the set of four lines that gave the best fit to a rigid asymmetric top Hamiltonian enabled the $1_{01}-2_{02}$ and $3_{13}-3_{22}$ transitions to be accurately predicted. A further 46 lines were then recorded. All lines were fitted to a Watson A-type rotational Hamiltonian [21]. The fits are summarized in table 5, and in tables S!, S2 and S3 of the Supplementary Material.

The initial scans had been made with the racemic mixture of butan-2,3-diol so the assignment of the transitions to the heterochiral molecule was confirmed with the pure samples; it was found that the assigned transitions could be observed with the meso $(R, S$ and $S, R)$ sample but not with the chiral $(R, R)$ sample. 
The next search focussed on the microwave spectra of the two mono-deutero-hydroxyl forms of the $\mathrm{G}_{\mathrm{l}} \mathrm{CM} / \mathrm{G}_{\mathrm{I}} \mathrm{MC}$ conformers. It was desirable to obtain information on these species as it was hoped that a Kraitchman analysis [22] of the rotational constants would confirm the assignment of the conformer to one of the ab initio predictions. It is likely that the errors between the $a b$ initio predictions and experimental rotational constants are similar for the parent and deuterated isotopomers. Hence, assuming that the conformer already observed was the $\mathrm{G}_{\mathrm{l}} \mathrm{CM} / \mathrm{G}_{\mathrm{r}} \mathrm{MC}$ species, it should be possible to improve the ab initio predictions of the rotational constants of the mono-deutero-hydroxyl species by comparison with the ab initio and experimental data on the parent isotopomer.

This predictive technique appeared to work, and allowed microwave spectra of two species with rotational constants similar to that of the parent isotopomer to be recorded. The transitions of these species exhibited narrow quadrupole splittings, arising because of the presence of the deuterium atom, which has a quadrupolar nucleus with a spin of 1 . The transitions of these species were fitted to a Hamiltonian identical to that used for the parent isotopomer except that it included the diagonal quadrupole coupling parameters, $\chi_{a a}$ and $\chi_{b b}$ $\chi_{c c}$. In total, 17 rotational transitions consisting of 47 hyperfine components were fitted for the isotopomer which was believed to have the proton accepting hydroxyl group deuterated and 17 rotational transitions consisting of 56 hyperfine components for the jsotopomer which was believed to be deuterated at the proton donating hydroxyl group. The resulting spectral parameters are given in table 5 .

\subsection{Experimental results II: Homochiral butan-2,3-diol}

Initial searches for the spectra of the GtCM homochiral conformer did not lead to a convincing assignment. This was believed to be due to a tunnelling motion of the hydroxyl groups that could connect two equivalent minima of any of the four lowest energy conformers 
of homochiral butan-2,3-diol. Hence, scans were performed to locate the spectra of the two mono-deutero-hydroxyl species, as the asymmetric deuteration should remove any effect of such tunnelling on the spectrum. It was hoped that the spectra of these deuterated species would yield accurate estimates of the rotational constants of the parent isotopomer.

Searches around the $a b$ initio predicted microwave transition frequencies for the deuterated isotopomers of the GtCM conformer yielded two sets of spectra. As for the heterochiral species, narrow hyperfine splittings resulting from the quadrupole moment of the deuterium nucleus were observable. Ten rotational transitions, divided into 26 hyperfine components, of each of these species were fitted to Watson A-type Hamiltonians. The spectral parameters are listed in table 6 , and the fits in tables S5 and S6.

\subsection{The tunnelling spectrum of homochiral butan-2,3-diol}

As in the $\mathrm{g}^{\prime} \mathrm{Ga}$ conformer of ethylene glycol, the GtCM conformer of homochiral butan-2,3-diol was expected to undergo a tunnelling motion that reverses the direction of the $\mu_{\mathrm{a}}$ and $\mu_{c}$ components of the dipole moment. Thus, the a and c-type microwave transitions should connect the two tunnelling states of the GtCM conformer, and these transitions should occur at frequencies approximately equal to a pure rotational transition difference plus or minus a tunnelling splitting. The b-type transitions link energy levels of the same tunnelling state and should be largely independent of the tunnelling splitting. The tunnelling motion is

illustrated in figure 5 and is related to the original structure by a rotation by $180^{\circ}$ around the baxis.

Coriolis forces complicate the spectrum by making the tunnelling splitting dependent on the rotational state of the molecule. If the spectrum of a molecule exhibiting a tunnelling motion through a potential barrier such as ethylene glycol or butan-2,3-diol is analysed with a rigid rotor approach then the rotational constants obtained will relate to the transition state, as 
where $E_{v}$ is the energy of the vibrational state, $\hat{\mathbf{H}}_{v v}$ connects levels of the same vibrational state and $\hat{\mathbf{H}}_{v v^{\prime}}$ connects levels of different vibrational states. Pickett has determined the required symmetric top matrix elements for equations 1 and 2, which are given in reference 25.

Christen et al. have employed both the IAM and RAS methods for their work on ethylene glycol [13 - 16]. The main advantages of the RAS method are that it can provide information on the tunnelling splitting even if no transitions across the tunnelling splitting have been recorded and that it can be applied without knowledge of the tunnelling path, 
whereas the IAM method must be set up differently for each tunnelling path considered. For these reasons the analysis of homochiral butan-2,3-diol presented in this chapter has utilized the RAS method, implemented with the SPFIT computer program of Pickett [26].

A useful diagnostic, which aids the assignment of microwave spectra, occurs when it is possible to observe "cycles" of transitions, which link two rotational energy levels by more than one path. If the assignment of the transitions is correct, the sum of the transition frequencies in each path should be equal to within the experimental error.

The predicted rotational constants provided by work on the mono-deutero-hydroxyl species indicated that two cycles of b-type transitions lay within the range of the spectrometer. Scans over frequency ranges centred on the predictions of these transitions yielded four cycles in total. These sixteen transitions were then fitted to an RAS Hamiltonian that included a set of rotational constants for each of the two tunnelling states, a tunnelling frequency and the Coriolis coupling constants $F_{a b}$ and $F_{b c}$.

Only two combinations of trial fits were then needed to deduce which two cycles of lines belonged to the lower, and which to the upper, tunnelling state. The cycles are illustrated in figure 6. A reasonable starting value of the tunnelling splitting $\left(\Delta_{t u n}\right)$ was deduced by fitting the sixteen transitions with values of $\Delta_{\text {tun }}$ between 0 and $7 \mathrm{GHz}$ in $0.5 \mathrm{GHz}$ steps. It was found that starting values of 1.0 and $1.5 \mathrm{GHz}$ both yielded a fit with a root mean square error of 9.6 $\mathrm{kHz}$ and $\Delta_{\text {tun }}=1024.39$ (65) MHz. The small error of this fit appeared to confirm that the two pairs of cycles had been correctly matched.

Using the parameters from this fit it proved possible to record transitions across the tunnelling; 20 a-type and 12 c-type transitions were found. A further 48 b-type lines were also observed and included in the final fit.

The five A-reduced quartic centrifugal distortion terms were also derived from this fit but, the differences between the centrifugal distortion constants of the two tunnelling states 
were too small to be determined from the observed transitions. The constants derived from the fit of the four b-type cycles and the final fit are displayed in table 7, and the fits to the spectrum in table S4.

\section{Discussion}

\subsection{Mass substitution analysis}

The position of a specific atom within a molecule may be deduced if the rotational constants, which arise when different isotopes are present at this position, are known. This is achieved via Kraitchman's substitution method [22]. This technique will be utilized below in an attempt to confirm which of the $a b$ initio structures most closely resembles the species that have been observed in the supersonic molecular beam. The difference in the moment of inertia between two isotopomers may be written [27]:

$$
\Delta I_{i}=\left(\frac{m \Delta m}{m+\Delta m}\right) r_{i}^{2}
$$

where $\Delta I_{i}$ is the difference in the $a, b$ or $c$ moment of inertia of the two species, $m$ is the mass of the parent species (approximately $90 \mathrm{u}$ in the case of butan-2,3-diol), $\Delta m$ is the change of mass involved in the substitution (approximately $1 \mathrm{u}$ for $\mathrm{H}$ substituted by D) and $r_{i}$ is the distance of the substituted atom from the principal axis to which $\Delta I_{i}$ relates.

This analysis assumes that the observed structures are not affected by the mass dependence of the vibrations of the molecule and also that the inertial axes are not significantly shifted by the change in mass. Co-ordinates relative to the three principal axes were thus deduced for the two hydrogen atoms in the observed homo and heterochiral conformers of butan-2,3-diol, and are displayed in tables 8 and 9 alongside the equivalent $a b$ initio results for the conformers predicted to have the lowest energies. 
The experimental results for the two conformers match very well with the co-ordinates for the lowest energy homo and heterochiral conformers respectively. As can be seen from figures 3 and 4, the only significant difference between the GtCM and GtMH homochiral conformers and the $\mathrm{G}_{\mathrm{l}} \mathrm{CM} / \mathrm{G}_{\mathrm{r}} \mathrm{MC}$ and $\mathrm{G}_{\mathrm{l}} \mathrm{MM} / \mathrm{G}_{\mathrm{r}} \mathrm{MM}$ heterochiral conformers is a rotation of the HOCC dihedral angle for the proton accepting $\mathrm{OH}$ group. The coordinates above reflect this; as expected, it is only the coordinates of the proton acceptor hydroxyl hydrogen that allow us to distinguish which conformer of each of these pairs has been observed.

The predicted electric dipole moment components of the heterochiral conformers, displayed in table 2, also support the conclusion that the $\mathrm{G}_{\mathrm{l}} \mathrm{CM} / \mathrm{G}_{\mathrm{r}} \mathrm{MC}$ conformer is the one observed. In both the $\mathrm{G}_{\mathrm{l}} \mathrm{HC} / \mathrm{G}_{\mathrm{r}} \mathrm{CH}$ and the $\mathrm{G}_{\mathrm{l}} \mathrm{MM} / \mathrm{G}_{\mathrm{r}} \mathrm{MM}$ conformers two of the dipole components are small. There is no way to measure the dipoles quantitatively in the microwave experiment that has been performed, but the fact the $\mathrm{a}, \mathrm{b}$ and $\mathrm{c}$-type transitions were all easily observable suggests that none of the dipole components were near zero. In the homochiral conformer the lowest energy ab initio structures all have similar dipoles and do not add further evidence to support the Kraitchman analysis. Full ab initio geometries of the observed $\underline{\text { conformers are given in tables S7 and S8 of the Supplementary Material. }}$

\subsection{Deuterium quadrupole coupling constants}

The inertial axis quadrupole coupling constants obtained from the microwave spectra provide information on the effect of the hydrogen bond on the hydroxyl groups in butan-2,3diol. These coupling constants are elements of the inertial axis quadrupole coupling tensor. If this tensor is transformed to its principal axes the coupling constants of the four deuterium atoms will be comparable. It seems reasonable to assume that the quadrupole tensor is approximately symmetric about the O-D bond. If this is the case it will have a coupling constant, $\chi$, associated with the bond axis and two non-unique coupling constants, $-\chi / 2$, 


\subsection{The tunnelling path of the GtCM conformer}

There are four possible combinations of $120^{\circ}$ and $240^{\circ}$ rotations of the hydroxyl groups that will interconvert the two equivalent minima of the GtCM/GtMC conformer. These paths are illustrated in figure 7 . Intuitively the path that involves a $120^{\circ}$ rotation of both hydroxyl 
groups appears to be the most favourable as it requires both hydroxyl hydrogens to pass over $\mathrm{C}-\mathrm{H}$ bonds, rather than $\mathrm{C}-\mathrm{C}$ bonds.

This guess at the most likely tunnelling path is supported by the microwave work of Christen et al., which has shown that the g'Ga conformer of ethylene glycol undergoes a concerted $120^{\circ}, 120^{\circ}$ tunnelling path, at a frequency of $7 \mathrm{GHz}$ [13]. The decrease in the tunnelling splitting between the two systems is assumed to indicate that the positions of the methyl groups in butan-2,3-diol must change slightly during the tunnelling process. This will increase the reduced mass involved in the tunnelling motion and decrease the tunnelling splitting.

\section{Concluding remarks}

The assignment of the two observed conformers of butan-2,3-diol to the conformational ground states of the homo and heterochiral species is supported by the Kraitchman analyses and the tunnelling properties of the homochiral species. These species have also accounted for all of the most intense observed transitions, as would be expected if they are indeed the most populated conformational states. The microwave spectrum of butan2,3-diol is, however, very dense and many weaker lines, which could arise from excited conformational states, uncommon isotopomers, rare gas-butan-2,3-diol complexes, dimers and higher clusters, are still unassigned.

\section{Acknowledgements}

The support of the EPSRC is gratefully acknowledged. We also thank Professor D. Christen for helpful discussions. 


\section{References}

[1] L. P. Kuhn, J. Am. Chem. Soc., 80, 5950 (1958).

[2] E. L. Eliel and S. H. Wilen, Stereochemistry of Organic Compounds, John Wiley \& Sons Inc., New York (1994).

[3] J. Grochowski, B. Rhys, P. Serda and U. Wagner, Tetrahedron: Asymmetry, 6, 2059 (1995).

[4] S. G. Davies, R. F. Newton and J. M. J. Williams, Tetrahedron Lett., 30, 2967 (1989).

[5] L. Angiolini, C. Carlini and E. Salatelli, Makromol. Chem., 193, 2883 (1992).

[6] K. Awano, T. Yanai, I. Watanabe, Y. Tagaki, T. Kitahara and K. Mori, Biosci. Biotechnol. Biochem., 59, 1251, (1995).

[7] A. Szarecka, M. Hoffmann, J. Rychlewski and U. J. Rychlewska, J. Mol. Struct., 374, 363 (1996).

[8] F. Wang and P. L. Polavarapu, J. Phys. Chem A, 105, 6991 (2001).

[9] W. Caminati and G. Corbelli, J. Mol. Spectrosc., 90, 572 (1981).

[10] P. E. Kristiansen, K. M. Marstokk and H. Møllendal, Acta Chem. Scand. A, 41, 403 (1987)

[11] K. M. Marstokk and H. Møllendal, J. Mol. Struct., 22, 301 (1974).

[12] E. Walder, A. Bauder and Hs. H. Günthard, Chem. Phys., 51, 223 (1980).

[13] D. Christen, L. H. Coudert, R. D. Suenram and F. J. Lovas, J. Mol. Spectrosc., 172, 57 (1995).

[14] D. Christen, L. H. Coudert, J. A. Larsson and D. Cremer, J. Mol. Spectrosc., 205, 185 (2001).

[15] D. Christen and H.S.P. Muller, PCCP, 5, 3600 (2003).

[16] H.S.P. Muller and D. Christen, J. Mol. Spectrosc. 5, 298 (2004).

[17] W. Caminati, J. Mol. Spectrosc., 86, 193 (1981). 
[18] T. J. L. Lockley, J. P. I. Hearn, A. K. King and B. J. Howard, J. Mol. Struct., 612, 199 (2002).

[19] Gaussian 98, Revision A.3, M. J. Frisch, G. W. Trucks, H. B. Schlegel et al. Gaussian, Inc., Pittsburgh PA, (1998).

[20] C.J. Whitham, R.J. Low and B.J. Howard, Chem. Phys. Lett. 286, 408 (1998).

[21] J.K.G. Watson Vibrational Spectra and Structure, Vol 6, Ed J.R. Durig (Elsevier) p.1 (1977).

[22] J. Kraitchman, Am. J. Phys., 21, 17 (1953).

[23] J. T. Hougen, J. Mol. Spectrosc., 114, 395 (1985).

[24] L. H. Coudert and J. T. Hougen, J. Mol. Spectrosc., 130, 86 (1988).

[25] H. M. Pickett, J. Chem. Phys., 56, 1715 (1972).

[26] H. M. Pickett, J. Mol. Spectrosc., 148, 371 (1991).

[27] H. W. Kroto, Molecular Rotation Spectra, (John Wiley \& Sons, London, 1975).

[28] W. Gordy and R. L. Cook, Microwave Molecular Spectra, (John Wiley \& Sons, New York, 1970).

[29] E. Hirota and Y. Kawashima, J. Mol. Spectrosc., 207, 243 (2001). 
Table 1: The energies of the conformers of $(R, S)$-butan-2,3-diol geometry optimized at the HF/6-311G level.

\begin{tabular}{|c|c|c|c|}
\hline Conformer & $E / E_{\mathrm{h}}$ & $E_{\mathrm{rel}} / \mathrm{cm}^{-1}$ & $\mathrm{H}$ bond \\
\hline $\mathrm{G}_{\mathrm{l}} \mathrm{CM} \equiv \mathrm{G}_{\mathrm{r}} \mathrm{MC}$ & -306.8810923 & 0 & Yes \\
\hline $\mathrm{G}_{\mathrm{l}} \mathrm{CC} \equiv \mathrm{G}_{\mathrm{r}} \mathrm{CC}$ & \multicolumn{2}{|c|}{ Converted to $\mathrm{G}_{\mathrm{l}} \mathrm{CM} \equiv \mathrm{G}_{\mathrm{r}} \mathrm{MC}$} & No \\
\hline $\mathrm{G}_{\mathrm{l}} \mathrm{HM} \equiv \mathrm{G}_{\mathrm{r}} \mathrm{MH}$ & \multicolumn{2}{|c|}{ Converted to $\mathrm{G}_{\mathrm{l}} \mathrm{CM} \equiv \mathrm{G}_{\mathrm{r}} \mathrm{MC}$} & No \\
\hline $\mathrm{G}_{\mathrm{l}} \mathrm{HC} \equiv \mathrm{G}_{\mathrm{r}} \mathrm{CH}$ & -306.8797009 & 305 & Yes \\
\hline $\mathrm{G}_{\mathrm{l}} \mathrm{MC} \equiv \mathrm{G}_{\mathrm{r}} \mathrm{CM}$ & \multicolumn{2}{|c|}{ Converted to $\mathrm{G}_{\mathrm{l}} \mathrm{HC} \equiv \mathrm{G}_{\mathrm{r}} \mathrm{CH}$} & No \\
\hline TCC & -306.8790738 & 443 & No \\
\hline $\mathrm{G}_{\mathrm{l}} \mathrm{MM} \equiv \mathrm{G}_{\mathrm{r}} \mathrm{MM}$ & -306.8790667 & 445 & Yes \\
\hline $\mathrm{G}_{l} \mathrm{MH} \equiv \mathrm{G}_{\mathrm{r}} \mathrm{HM}$ & \multicolumn{2}{|c|}{ Converted to $\mathrm{G}_{\mathrm{l}} \mathrm{HH} \equiv \mathrm{G}_{\mathrm{r}} \mathrm{HH}$} & No \\
\hline $\mathrm{G}_{\mathrm{l}} \mathrm{HH} \equiv \mathrm{G}_{\mathrm{r}} \mathrm{HH}$ & -306.8776857 & 748 & Yes \\
\hline $\mathrm{THC} \equiv \mathrm{TCH}$ & -306.8773939 & 812 & No \\
\hline $\mathrm{TMC} \equiv \mathrm{TCM}$ & -306.8773328 & 825 & No \\
\hline TMM & -306.8767426 & 955 & No \\
\hline THH & -306.8760264 & 1112 & No \\
\hline $\mathrm{THM} \equiv \mathrm{TMH}$ & -306.8752805 & 1276 & No \\
\hline $\mathrm{G}_{\mathrm{l}} \mathrm{CH} \equiv \mathrm{G}_{\mathrm{r}} \mathrm{HC}$ & -306.8701875 & 2393 & No \\
\hline
\end{tabular}


Table 2: The properties of the lowest energy conformers of $(R, S)$-butan-2,3-diol optimized at $\mathrm{MP} 2 / 6-311++\mathrm{G}^{* *}$.

\begin{tabular}{c|cccccccc} 
Conformer & $A / \mathrm{MHz}$ & $B / \mathrm{MHz}$ & $C / \mathrm{MHz}$ & $\mu_{\mathrm{a}} / \mathrm{D}$ & $\mu_{\mathrm{b}} / \mathrm{D}$ & $\mu_{\mathrm{c}} / \mathrm{D}$ & $E / E_{\mathrm{h}}$ & $\begin{array}{c}E_{\mathrm{rel}} / \\
\mathrm{cm}^{-1}\end{array}$ \\
\hline $\mathrm{G}_{\mathrm{l}} \mathrm{CM} \equiv \mathrm{G}_{\mathrm{r}} \mathrm{MC}$ & 4665.9 & 2871.9 & 2350.2 & 1.7 & 1.9 & 1.0 & -308.1263317 & 0 \\
$\mathrm{G}_{\mathrm{l}} \mathrm{HC} \equiv \mathrm{G}_{\mathrm{r}} \mathrm{CH}$ & 4607.4 & 2843.9 & 2360.0 & 2.9 & 0.4 & 0.0 & -308.1249394 & 306 \\
$\mathrm{G}_{\mathrm{l}} \mathrm{MM} \equiv \mathrm{G}_{\mathrm{r}} \mathrm{MM}$ & 4669.1 & 2830.7 & 2344.8 & 0.2 & 0.5 & 2.5 & -308.125464 & 190 \\
$\mathrm{G}_{1} \mathrm{HH} \equiv \mathrm{G}_{\mathrm{r}} \mathrm{HH}$ & 4557.6 & 2852.7 & 2331.7 & 1.9 & 2.2 & 0.9 & -308.1241772 & 473 \\
$\mathrm{TCC}$ & 4572.7 & 3107.8 & 1999.6 & 0.0 & 0.0 & 0.0 & -308.1232344 & 680
\end{tabular}


Table 3: The energies of the conformers of $(S, S)$ and $(R, R)$-butan-2,3-diol geometry optimized at the HF/6-311G level.

\begin{tabular}{|c|c|c|c|}
\hline Conformer & $E / E_{\mathrm{H}}$ & $E_{\text {rel }} / \mathrm{cm}^{-1}$ & $\mathrm{H}$ bond \\
\hline $\mathrm{GtCM}$ & -306.8815422 & 0 & Yes \\
\hline GtHC & \multicolumn{2}{|c|}{ Converted to GtCM } & No \\
\hline THC & -306.8807831 & 167 & Yes \\
\hline GtMH & -306.8794134 & 467 & Yes \\
\hline THM & -306.8788301 & 595 & Yes \\
\hline $\mathrm{GtCC}$ & \multicolumn{2}{|c|}{ Converted to GtMM } & No \\
\hline GtMM & -306.8786928 & 625 & No \\
\hline $\mathrm{GgCC}$ & -306.877986 & 780 & No \\
\hline $\mathrm{THH}$ & -306.8778043 & 820 & No \\
\hline TCC & \multicolumn{2}{|c|}{ Converted to $\mathrm{THH}$} & No \\
\hline GgMC & -306.876508 & 1105 & No \\
\hline $\mathrm{GgHC}$ & -306.8759726 & 1222 & No \\
\hline $\mathrm{GgHM}$ & -306.8753539 & 1358 & No \\
\hline GgMM & -306.8750526 & 1424 & No \\
\hline TMM & -306.737299 & 1715 & No \\
\hline $\mathrm{GtHH}$ & -306.736728 & 1727 & No \\
\hline $\mathrm{GgHH}$ & -306.733768 & 1792 & No \\
\hline TMC & -306.713747 & 2231 & No \\
\hline
\end{tabular}


Table 4: The properties of the lowest energy conformers of $(S, S)$ and $(R, R)$-butan-2,3-diol optimized at MP2 / 6-311++G**.

\begin{tabular}{c|cccccccc} 
Conformer & $A / \mathrm{MHz}$ & $B / \mathrm{MHz}$ & $C / \mathrm{MHz}$ & $\mu_{\mathrm{a}} / \mathrm{D}$ & $\mu_{b} / \mathrm{D}$ & $\mu_{c} / \mathrm{D}$ & $E / E_{\mathrm{h}}$ & $\begin{array}{c}E_{\mathrm{rel}} / \\
\mathrm{cm}^{-1}\end{array}$ \\
\hline GtCM & 4578.7 & 3090.9 & 1994.6 & 2.5 & 1.6 & 0.7 & -308.126606 & 0 \\
GtMH & 4571.1 & 3061.2 & 1987.8 & 1.6 & 2.0 & 1.4 & -308.1260706 & 117 \\
THC & 4773.1 & 2765.2 & 2414.4 & 1.9 & 1.4 & 1.3 & -308.1255081 & 240 \\
THM & 4763.2 & 2739.6 & 2399.1 & 0.5 & 2.0 & 0.7 & -308.1243612 & 492 \\
GtMM & 4612.6 & 3007.5 & 1985.0 & 0.0 & 0.7 & 0.0 & -308.1241789 & 533
\end{tabular}


Table 5: Spectral parameters of the $\mathrm{G}_{\mathrm{l}} \mathrm{CM} / \mathrm{G}_{\mathrm{r}} \mathrm{CM}$ conformer of heterochiral butan-2,3-diol.

\begin{tabular}{|c|c|c|c|}
\hline & Parent & Proton Donor & Proton Acceptor \\
& Isotopomer & Group Deuterated & Group Deuterated \\
\hline
\end{tabular}

\begin{tabular}{|c|c|c|c|}
\hline$A / \mathrm{MHz}$ & $4640.0465(2)$ & $4497.4826(8)$ & $4629.2594(8)$ \\
\hline$B / \mathrm{MHz}$ & $2840.8899(2)$ & $2832.7649(7)$ & $2745.8061(9)$ \\
\hline$C / \mathrm{MHz}$ & $2343.3848(2)$ & $2312.9114(7)$ & $2278.3988(8)$ \\
\hline
\end{tabular}

\begin{tabular}{|c|c|c|c|}
\hline$\Delta_{J} / \mathrm{kHz}$ & $0.932(9)$ & $0.993(23)$ & $0.850(30)$ \\
\hline$\Delta_{J} / \mathrm{kHz}$ & $-1.165(5)$ & $-1.06(9)$ & $-0.94(13)$ \\
\hline$\Delta_{K} / \mathrm{kHz}$ & $1.616(11)$ & $0.63(20)$ & $1.47(19)$ \\
\hline$\delta_{J} / \mathrm{kHz}$ & $0.240(6)$ & $0.251(13)$ & $0.316(22)$ \\
\hline$\delta_{K} / \mathrm{kHz}$ & $3.481(11)$ & $3.10(24)$ & $2.95(36)$ \\
\hline
\end{tabular}

\begin{tabular}{|c|c|c|c|}
\hline$\chi_{a a} / \mathrm{kHz}$ & - & $117.1(14)$ & $219.5(15)$ \\
\hline$\left(\chi_{b b}-\chi_{c c}\right) / \mathrm{kHz}$ & - & $100.4(40)$ & $43.5(38)$ \\
\hline
\end{tabular}

\begin{tabular}{|c|c|c|c|}
\hline$N^{a}$ & 52 & 56 & 47 \\
\hline$\sigma_{r m s} / \mathrm{kHz}$ & 1.7 & 4.3 & 3.1 \\
\hline
\end{tabular}

${ }^{a}$ The total number of lines included in the fit. 
Table 6: Spectral parameters of the deuterohydroxyl isotopomers of the GtCM conformer of homochiral butan-2,3-diol.

\begin{tabular}{|l|c|c|}
\hline & Proton Donor Group & Proton Acceptor Group \\
Deuterated & Deuterated \\
\hline
\end{tabular}

\begin{tabular}{|c|c|c|}
\hline$A / \mathrm{MHz}$ & $4437.9005(9)$ & $4505.6211(13)$ \\
\hline$B / \mathrm{MHz}$ & $3061.3386(10)$ & $2987.7452(7)$ \\
\hline$C / \mathrm{MHz}$ & $1956.2602(4)$ & $1940.6420(7)$ \\
\hline
\end{tabular}

\begin{tabular}{|c|c|c|}
\hline$\Delta_{J} / \mathrm{kHz}$ & $0.455(20)$ & $0.442(28)$ \\
\hline$\Delta_{J K} / \mathrm{kHz}$ & -0.580 & $-0.56(11)$ \\
\hline$\Delta_{K} / \mathrm{kHz}$ & $1.41(25)$ & $1.3(8)$ \\
\hline$\delta_{J} / \mathrm{kHz}$ & $0.170(17)$ & $0.18(2)$ \\
\hline$\delta_{K} / \mathrm{kHz}$ & $0.361^{\mathrm{a}}$ & $0.361^{\mathrm{a}}$ \\
\hline
\end{tabular}

\begin{tabular}{|c|c|c|}
\hline$\chi_{a a} / \mathrm{kHz}$ & $16.9(34)$ & $166.9(19)$ \\
\hline$\left(\chi_{b b}-\chi_{c c}\right) / \mathrm{kHz}$ & $275.8(34)$ & $-80.0(52)$ \\
\hline
\end{tabular}

\begin{tabular}{|c|c|c|}
\hline$N$ & 26 & 26 \\
\hline$\sigma_{\mathrm{rms}} / \mathrm{kHz}$ & 2.6 & 1.9 \\
\hline
\end{tabular}

${ }^{\mathrm{a}}$ Constrained to the value for the parent isotopomer (table 4.7). 
Table 7: Spectral parameters of the GtCM conformer of homochiral butan-2,3-diol.

\begin{tabular}{|c|c|c|}
\hline & Full Fit & Fit of b-type cycles \\
\hline$A / \mathrm{MHz}$ & $4574.8694(2)$ & $4574.8330(11)$ \\
\hline$B / \mathrm{MHz}$ & 3072.5964 (2) & $3072.5832(3)$ \\
\hline$C / \mathrm{MHz}$ & $1987.0638(2)$ & $1987.0550(3)$ \\
\hline
\end{tabular}

\begin{tabular}{|c|c|c|}
\hline$\Delta A / \mathrm{kHz}$ & $12.46(8)$ & $23.6(9)$ \\
\hline$\Delta B / \mathrm{kHz}$ & $14.62(4)$ & $26.1(4)$ \\
\hline$\Delta C / \mathrm{kHz}$ & $4.28(6)$ & $2.5(3)$ \\
\hline
\end{tabular}

\begin{tabular}{|c|c|c|}
\hline$\Delta_{J} / \mathrm{kHz}$ & $0.468(6)$ & - \\
\hline$\Delta_{J K} / \mathrm{kHz}$ & $-0.580(8)$ & - \\
\hline$\Delta_{K} / \mathrm{kHz}$ & $1.446(7)$ & - \\
\hline$\delta_{J} / \mathrm{kHz}$ & $0.1672(14)$ & - \\
\hline$\delta_{K} / \mathrm{kHz}$ & $0.361(7)$ & \\
\hline
\end{tabular}

\begin{tabular}{|c|c|c|}
\hline$\Delta_{\text {tun }} / \mathrm{MHz}$ & $1011.9781(6)$ & $1024.4(7)$ \\
\hline$F_{a b} / \mathrm{MHz}$ & $10.9472(13)$ & $11.444(18)$ \\
\hline$F_{b c} / \mathrm{MHz}$ & $8.3800(4)$ & $8.356(14)$ \\
\hline
\end{tabular}

\begin{tabular}{|c|c|c|}
\hline$N$ & 96 & 16 \\
\hline$\sigma_{r m s} / \mathrm{kHz}$ & 0.67 & 9.6 \\
\hline
\end{tabular}


Table 8: Principal axis coordinates of the hydroxyl hydrogen atoms in the conformers of heterochiral butan-2,3-diol from isotopic substitution and ab initio calculations.

\begin{tabular}{|c|c|c|c|c|c|c|}
\hline & \multicolumn{3}{|c|}{ Donor OH hydrogen } & \multicolumn{2}{c|}{ Acceptor OH hydrogen } \\
& $a / \AA$ & $b / \AA$ & $c / \AA$ & $a / \AA$ & $b / \AA$ & $c / \AA$ \\
\hline Exp. & $0^{\mathrm{a}}$ & \pm 1.710 & \pm 0.753 & \pm 2.469 & \pm 0.352 & \pm 0.365 \\
\hline $\mathrm{G}_{\mathrm{l}} \mathrm{CM} \equiv \mathrm{G}_{\mathrm{r}} \mathrm{MC}$ & -0.053 & -1.659 & 0.817 & 2.469 & -0.415 & -0.243 \\
\hline $\mathrm{G}_{\mathrm{l}} \mathrm{HC} \equiv \mathrm{G}_{\mathrm{r}} \mathrm{CH}$ & 1.424 & -1.310 & 0.232 & -1.515 & -1.606 & 0.87 \\
\hline $\mathrm{G}_{\mathrm{l}} \mathrm{MM} \equiv \mathrm{G}_{\mathrm{r}} \mathrm{MM}$ & -0.019 & -1.583 & 0.886 & 1.619 & -1.206 & -1.169 \\
\hline $\mathrm{G}_{\mathrm{l}} \mathrm{HH} \equiv \mathrm{G}_{\mathrm{r}} \mathrm{HH}$ & 1.352 & -1.352 & 0.230 & -0.998 & -0.630 & 1.518 \\
\hline
\end{tabular}

${ }^{\mathrm{a}}$ The square of this coordinate was determined to be small and negative, so it has been set to zero.

Table 9: Principal axis coordinates of the hydroxyl hydrogen atoms in the conformers of homochiral butan-2,3-diol from isotopic substitution and ab initio calculations.

\begin{tabular}{|c|c|c|c|c|c|c|}
\hline & \multicolumn{3}{|c|}{ Donor OH hydrogen } & \multicolumn{2}{c|}{ Acceptor OH hydrogen } \\
\hline & $a / \AA$ & $b / \AA$ & $c / \AA$ & $a / \AA$ & $b / \AA$ & $c / \AA$ \\
\hline Exp. & \pm 0.779 & \pm 1.856 & \pm 0.069 & \pm 2.140 & \pm 1.254 & \pm 0.380 \\
\hline GtCM & 0.760 & -1.857 & -0.023 & -2.121 & -1.287 & 0.393 \\
\hline GtMH & -0.720 & -1.853 & -0.032 & 1.678 & -1.083 & 0.916 \\
\hline THC & 0.595 & -0.589 & 1.503 & -1.631 & 1.395 & 0.923 \\
\hline
\end{tabular}

26 
Table 10: Calculated axial deuterium quadrupole coupling constants of the conformers of butan-2,3-diol.

\begin{tabular}{|c|c|c|c|c|}
\hline & \multicolumn{2}{|c|}{$\mathrm{G}_{\mathrm{l}} \mathrm{CM} / \mathrm{G}_{\mathrm{r}} \mathrm{MC}$} & \multicolumn{2}{c|}{$\mathrm{GtCM}$} \\
\hline & Donor & Acceptor & Donor & Acceptor \\
\hline$\theta$ & $35.8^{\circ}$ & $23.7^{\circ}$ & $49.2^{\circ}$ & $31.8^{\circ}$ \\
\hline$\chi / \mathrm{kHz}$ & 240 & 290 & 121 & 287 \\
\hline
\end{tabular}




\section{Figure captions.}

Figure 1. The hydrogen bonded conformations of meso and racemic butan-2,3-diol.

Figure 2. A nomenclature for the conformations of butan-2,3-diol.

Figure 3. The lowest energy structural minima of the heterochiral butan-2,3-diol (together with relative MP2/6-311++G** energies).

Figure 4. The three lowest energy structural minima of homochiral butan-2,3-diol (together with relative MP2/6-311++G** energies).

Figure 5. The tunnelling motion and approximate principal inertial axes of the GtCM conformer of butan-2,3-diol.

Figure 6. The b-type cycles of upper and lower tunnelling states of the GtCM conformer of butan-2,3-diol.

Figure 7. The four likely tunnelling paths of the GtCM conformer of butan-2,3-ol.

Figure 1. The hydrogen bonded conformations of meso and racemic butan-2,3-diol.<smiles>CC1C2CC3(C)OCOC3C1C2C</smiles>

Racemic $(R, R$ and $S, S)$<smiles>CC1C2COC3(COC23)C1C</smiles>

Meso $(R, S$ and $S, R)$ 
Figure 2. A nomenclature for the conformations of butan-2,3-diol.

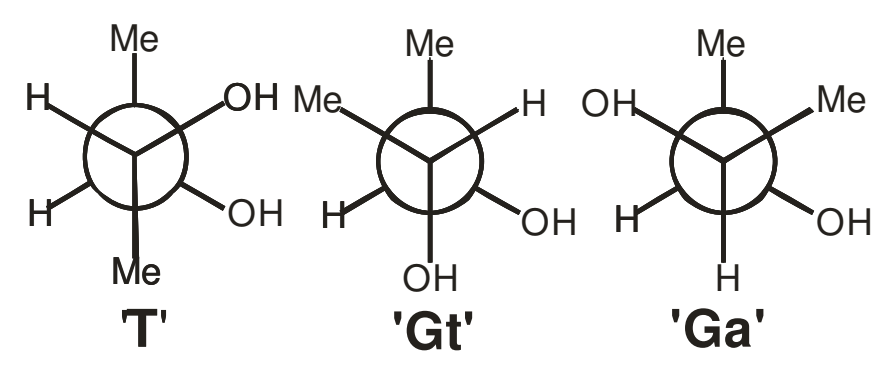<smiles>CC1C(O)C(O)C2CC1C(O)C2C</smiles>

T'<smiles>CC1CC2CC1C(O)C(O)C2C</smiles><smiles>CC1C(O)C2CCC1C(O)C2C</smiles>

' $\mathrm{G}_{\mathrm{r}}$ '<smiles>Cc1cc(O)ccc1[14CH3]</smiles><smiles>Cc1ccc(C=O)c(O)c1</smiles><smiles>Cc1cccc(O)c1C=O</smiles> 
Figure 3. The lowest energy structural minima of the heterochiral butan-2,3-diol (together with relative MP2/6-311++G** energies).

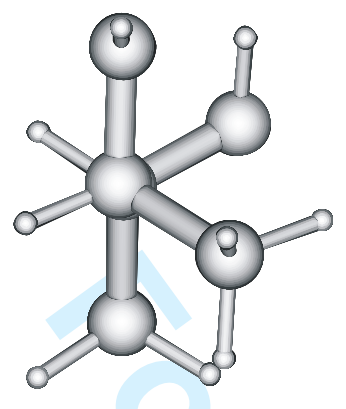

$\mathrm{G}_{1} \mathrm{CM} / \mathrm{G}_{\mathrm{r}} \mathrm{MC}$

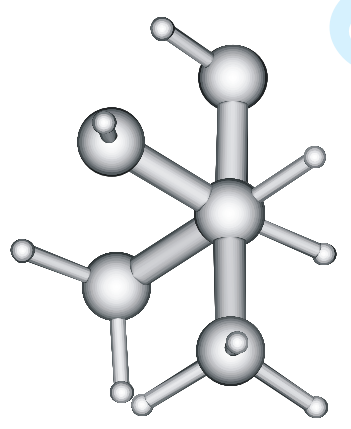

$\mathrm{G}_{1} \mathrm{HC} / \mathrm{G} \mathrm{CH}$

$+306 \mathrm{~cm}^{-1}$

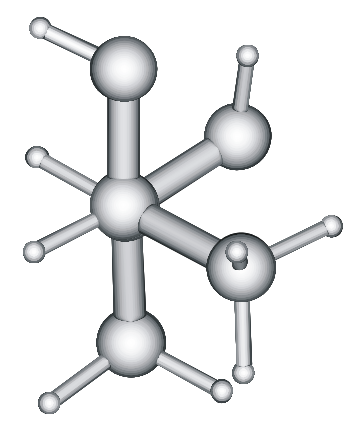

$\mathrm{G}_{\mathrm{P}} \mathrm{MM} / \mathrm{G}_{\mathrm{r}} \mathrm{MM}$

$+190 \mathrm{~cm}^{-1}$

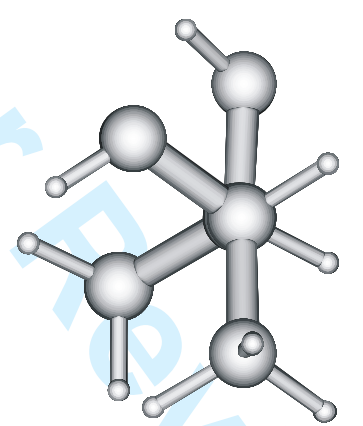

$\mathrm{G}_{\mathrm{l}} \mathrm{HH} / \mathrm{G}_{\mathrm{r}} \mathrm{HH}$

$+473 \mathrm{~cm}^{-1}$ 
Figure 4. The three lowest energy structural minima of homochiral butan-2,3-diol (together with relative MP2/6-311++G** energies).

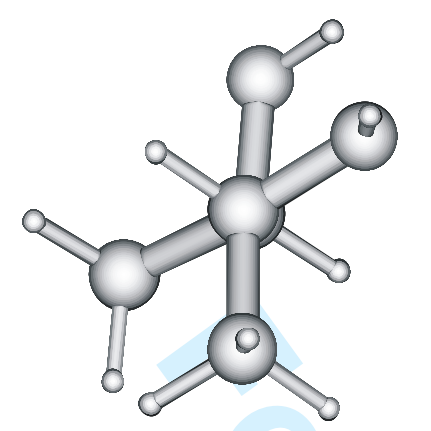

GtCM

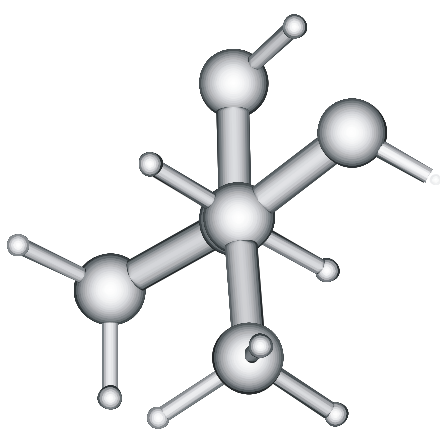

GtMH

$+117 \mathrm{~cm}^{-1}$

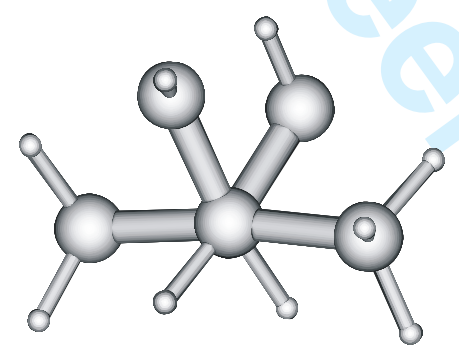

THC/TCH

$+240 \mathrm{~cm}^{-1}$ 
Figure 5. The tunnelling motion and approximate principal inertial axes of the GtCM conformer of butan-2,3-diol.

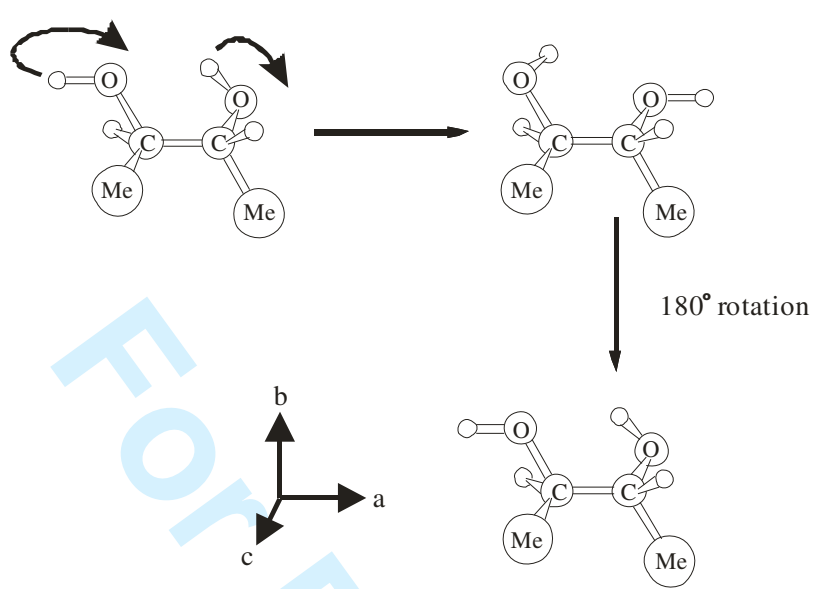


Figure 6. The b-type cycles of upper and lower tunnelling states of the GtCM conformer of butan-2,3-diol.

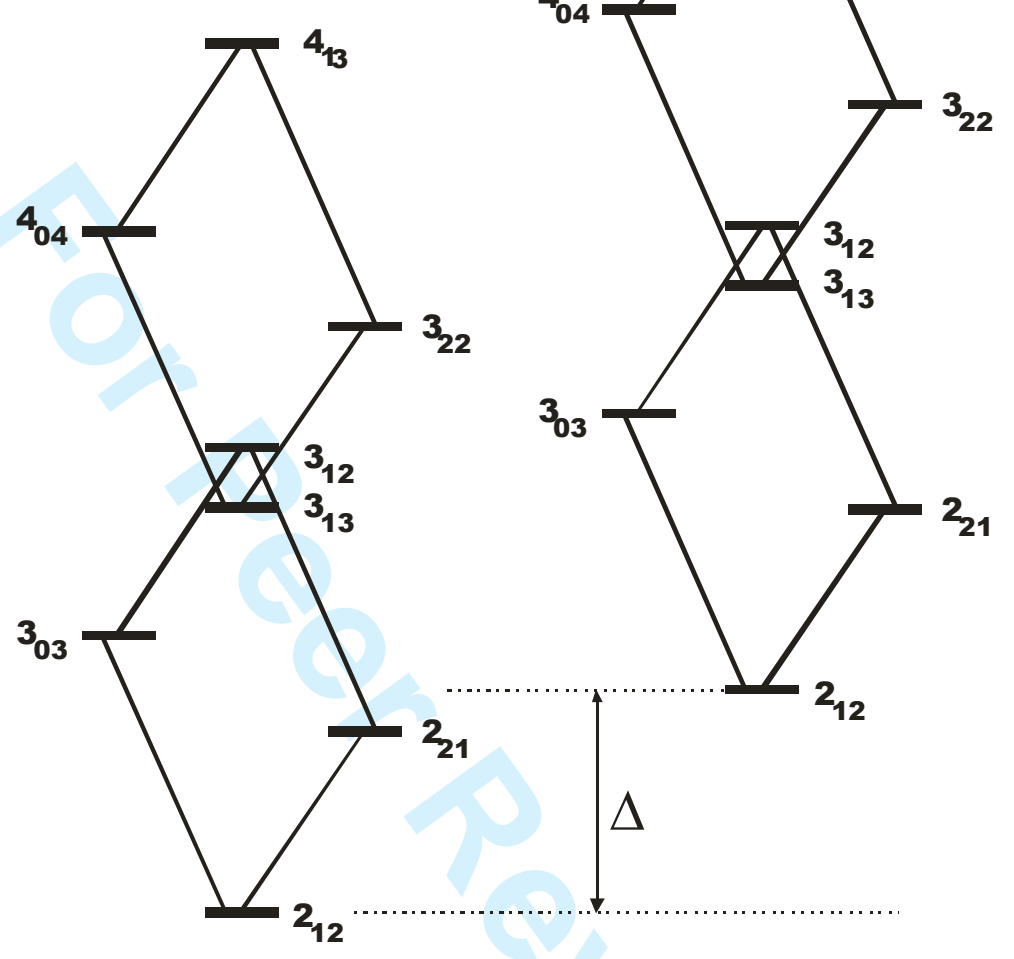


Figure 7. The four likely tunnelling paths of the GtCM conformer of butan-2,3-ol.
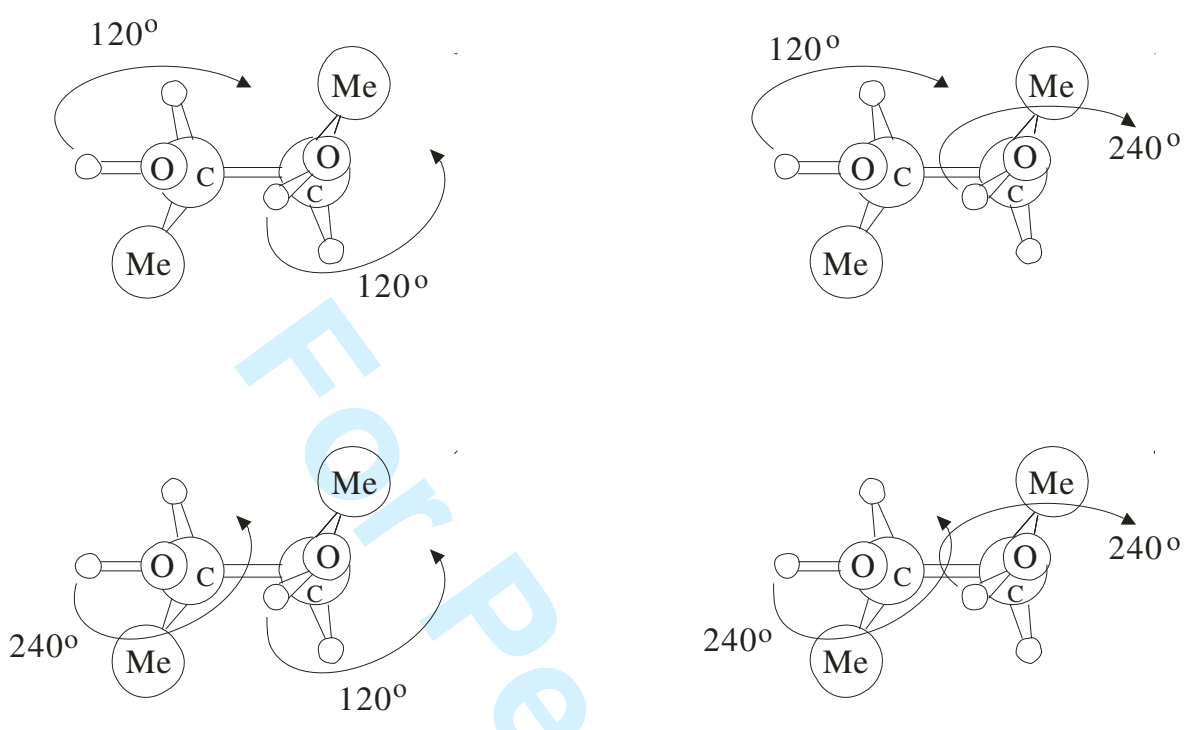


\title{
Supplementary Material
}

\author{
Chiral recognition in a single molecule: A study of homo and \\ heterochiral butan-2,3-diol by Fourier transform microwave \\ spectroscopy.
}

\section{J. Paul I. Hearn and Brian J. Howard.}

\author{
Physical and Theoretical Chemistry Laboratory \\ Department of Chemistry \\ Oxford University \\ South Parks Road \\ Oxford, OX1 3QZ \\ United Kingdom
}




\title{
Microwave transitions of heterochiral butan-2,3-diol.
}

\author{
Table S1: Fitted microwave transitions of the parent isotopomer of the $\mathrm{G}_{\mathrm{l}} \mathrm{CM} / \mathrm{G}_{\mathrm{r}} \mathrm{MC}$ \\ conformer of butan-2,3-diol.
}

$\begin{array}{cccccccc}J^{\prime} & K_{a}^{\prime} & K_{c}^{\prime} & J^{\prime \prime} & K_{a}{ }^{\prime \prime} & K_{c}^{\prime \prime} & v_{\mathrm{obs}} / \mathrm{MHz} & v_{\mathrm{obs}}{ }^{-} v_{\mathrm{calc}} / \mathrm{MHz} \\ 2 & 2 & 1 & 2 & 1 & 2 & 6889.9522 & -0.0001 \\ 1 & 1 & 1 & 0 & 0 & 0 & 6983.4357 & -0.0005 \\ 5 & 1 & 4 & 5 & 0 & 5 & 7480.6408 & 0.0002 \\ 1 & 1 & 0 & 0 & 0 & 0 & 7480.9263 & 0.0009 \\ 3 & 2 & 2 & 3 & 1 & 3 & 7687.9390 & -0.0016 \\ 3 & 2 & 1 & 3 & 1 & 3 & 8118.4675 & 0.0006 \\ 5 & 3 & 3 & 5 & 2 & 3 & 8458.1902 & 0.0000 \\ 2 & 0 & 2 & 1 & 1 & 1 & 8479.7020 & -0.0003 \\ 9 & 3 & 6 & 9 & 2 & 7 & 8492.9441 & 0.0008 \\ 3 & 2 & 2 & 3 & 0 & 3 & 8622.1922 & -0.0009 \\ 4 & 2 & 3 & 4 & 1 & 4 & 8765.1702 & -0.0002 \\ 4 & 2 & 3 & 4 & 0 & 4 & 9314.5210 & -0.0000 \\ 4 & 3 & 2 & 4 & 2 & 2 & 9322.0121 & 0.0000 \\ 4 & 3 & 1 & 4 & 2 & 2 & 9392.7108 & 0.0004 \\ 3 & 3 & 1 & 3 & 2 & 1 & 9860.7390 & -0.0021 \\ 2 & 1 & 2 & 1 & 1 & 1 & 9871.0407 & -0.0000 \\ 2 & 0 & 2 & 1 & 0 & 1 & 10278.8678 & 0.0002 \\ 3 & 3 & 1 & 3 & 2 & 2 & 10291.2655 & -0.0019 \\ 5 & 2 & 4 & 5 & 0 & 5 & 10401.9173 & 0.0027 \\ 4 & 3 & 2 & 4 & 2 & 3 & 10514.1085 & 0.0004 \\ 4 & 3 & 1 & 4 & 2 & 3 & 10584.8073 & 0.0008 \\ 2 & 1 & 1 & 1 & 1 & 0 & 10866.0081 & 0.0005\end{array}$




$\begin{array}{cccccccc}J^{\prime} & K_{a}^{\prime} & K_{c}^{\prime} & J^{\prime \prime} & K_{a}{ }^{\prime \prime} & K_{c}^{\prime \prime} & v_{\mathrm{obs}} / \mathrm{MHz} & v_{\mathrm{obs}}{ }^{-} v_{\mathrm{cal}} / \mathrm{MHz} \\ 5 & 3 & 3 & 5 & 2 & 4 & 10928.4808 & 0.0009 \\ 5 & 3 & 2 & 5 & 2 & 4 & 11200.4100 & 0.0012 \\ 2 & 1 & 2 & 1 & 0 & 1 & 11670.2057 & -0.0003 \\ 6 & 2 & 5 & 6 & 1 & 6 & 11697.2907 & 0.0010 \\ 9 & 2 & 7 & 9 & 1 & 8 & 12325.1072 & -0.0017 \\ 3 & 0 & 3 & 2 & 1 & 1 & 12328.0538 & -0.0006 \\ 8 & 3 & 6 & 8 & 2 & 7 & 13717.6081 & 0.0004 \\ 3 & 0 & 3 & 2 & 1 & 2 & 13820.5112 & 0.0007 \\ 5 & 3 & 3 & 5 & 1 & 4 & 13849.7545 & 0.0006 \\ 5 & 4 & 2 & 5 & 3 & 2 & 13912.1566 & 0.0005 \\ 4 & 4 & 1 & 4 & 3 & 1 & 14130.5068 & -0.0017 \\ 4 & 4 & 0 & 4 & 3 & 1 & 14131.4873 & 0.0014 \\ 5 & 4 & 2 & 5 & 3 & 3 & 14184.0861 & 0.0010 \\ 5 & 4 & 1 & 5 & 3 & 3 & 14192.7711 & 0.0003 \\ 4 & 4 & 1 & 4 & 3 & 2 & 14201.2059 & -0.0010 \\ 4 & 4 & 0 & 4 & 3 & 2 & 14202.1854 & 0.0012 \\ 3 & 1 & 3 & 2 & 1 & 2 & 14754.7636 & 0.0006 \\ 3 & 0 & 3 & 2 & 0 & 2 & 15211.8499 & 0.0010 \\ 3 & 2 & 2 & 2 & 2 & 1 & 15552.7531 & 0.0018 \\ 3 & 2 & 1 & 2 & 2 & 0 & 15893.6280 & 0.0023 \\ 4 & 0 & 4 & 3 & 1 & 2 & 16065.4788 & -0.0001 \\ 3 & 1 & 3 & 2 & 0 & 2 & 16146.1025 & 0.0011 \\ 3 & 1 & 2 & 2 & 1 & 1 & 16236.8898 & 0.0014 \\ 2 & 2 & 1 & 1 & 1 & 0 & 16263.5038 & -0.0001 \\ 2 & 2 & 0 & 1 & 1 & 0 & 16353.1558 & 0.0001 \\ 4 & 1 & 3 & 3 & 2 & 1 & 16374.9674 & 0.0028 \\ 2 & 2 & 1 & 1 & 1 & 1 & 16760.9933 & 0.0002 \\ 4 & 1 & 3 & 3 & 2 & 2 & 16805.4857 & -0.0052 \\ 2 & 2 & 0 & 1 & 1 & 1 & 16850.6374 & -0.0076 \\ 5 & 7 & 12 & 4 & 8 & 13861.7169 & -0.0008\end{array}$


Table S2: Fitted microwave transitions of the isotopomer of the $\mathrm{G}_{\mathrm{l}} \mathrm{CM} / \mathrm{G}_{\mathrm{r}} \mathrm{MC}$ conformer of butan-2,3-diol with deuteration at the proton donor hydroxyl group.

$\begin{array}{cccccccccc}J^{\prime} & K_{a}^{\prime} & K_{c}^{\prime} & F^{\prime} & J^{\prime \prime} & K_{a}^{\prime \prime} & K_{c}^{\prime \prime} & F^{\prime \prime} & V_{\mathrm{obs}} / \mathrm{MHz} & V_{\mathrm{obs}}-v_{\mathrm{cal}} / \mathrm{MHz} \\ 1 & 0 & 1 & 1 & 0 & 0 & 0 & 1 & 5145.6937 & -0.0079 \\ 1 & 0 & 1 & 0 & 0 & 0 & 0 & 1 & 5145.6191 & 0.0053 \\ 1 & 0 & 1 & 2 & 0 & 0 & 0 & 1 & 5145.6652 & -0.0013 \\ 1 & 1 & 0 & 1 & 0 & 0 & 0 & 1 & 7330.2081 & -0.0026 \\ 1 & 1 & 0 & 2 & 0 & 0 & 0 & 1 & 7330.2462 & 0.0029 \\ 1 & 1 & 1 & 0 & 0 & 0 & 0 & 1 & 6810.4087 & 0.0057 \\ 1 & 1 & 1 & 1 & 0 & 0 & 0 & 1 & 6810.3858 & -0.0109 \\ 1 & 1 & 1 & 2 & 0 & 0 & 0 & 1 & 6810.3985 & -0.0007 \\ 2 & 0 & 2 & 1 & 1 & 0 & 1 & 1 & 10187.3653 & 0.0015 \\ 2 & 0 & 2 & 1 & 1 & 0 & 1 & 0 & 10187.4528 & 0.0011 \\ 2 & 0 & 2 & 2 & 1 & 0 & 1 & 1 & 10187.4268 & -0.0007 \\ 2 & 0 & 2 & 3 & 1 & 0 & 1 & 2 & 10187.4174 & -0.0043 \\ 2 & 1 & 1 & 1 & 1 & 1 & 0 & 0 & 10811.0980 & -0.0037 \\ 2 & 1 & 1 & 2 & 1 & 1 & 0 & 1 & 10811.1974 & 0.0099 \\ 2 & 1 & 1 & 3 & 1 & 1 & 0 & 2 & 10811.1526 & 0.0004 \\ 2 & 1 & 2 & 1 & 1 & 0 & 1 & 1 & 11436.1619 & -0.0001 \\ 2 & 1 & 2 & 2 & 1 & 0 & 1 & 2 & 11436.2476 & -0.0039 \\ 2 & 1 & 2 & 1 & 1 & 0 & 1 & 0 & 11436.2476 & -0.0022 \\ 2 & 1 & 2 & 2 & 1 & 0 & 1 & 1 & 11436.2142 & -0.0022 \\ 2 & 1 & 2 & 3 & 1 & 0 & 1 & 2 & 11436.2142 & -0.0023 \\ 2 & 1 & 1 & 1 & 1 & 0 & 1 & 0 & 12995.7823 & 0.0021 \\ 2 & 1 & 1 & 2 & 1 & 0 & 1 & 1 & 12995.6941 & -0.0024 \\ 2 & 1 & 1 & 3 & 1 & 0 & 1 & 2 & 12995.7325 & 0.0035 \\ 2 & 2 & 1 & 1 & 1 & 1 & 0 & 1 & 15805.4072 & 0.0021 \\ 2 & 2 & 1 & 2 & 1 & 1 & 0 & 2 & 15805.3191 & 0.0052 \\ 2 & 2 & 1 & 2 & 1 & 1 & 0 & 1 & 15805.3492 & 0.0026 \\ 2 & 2 & 1 & 3 & 1 & 1 & 0 & 2 & 15805.3492 & -0.0024\end{array}$




$\begin{array}{cccccccccc}J^{\prime} & K_{a}^{\prime} & K_{c}^{\prime} & F^{\prime} & J^{\prime \prime} & K_{a}{ }^{\prime \prime} & K_{c}{ }^{\prime \prime} & F^{\prime \prime} & v_{\mathrm{obs}} / \mathrm{MHz} & v_{\mathrm{obs}}{ }^{-} v_{\mathrm{calc}} / \mathrm{MHz} \\ 3 & 2 & 1 & 2 & 2 & 2 & 0 & 1 & 15827.7127 & -0.0006 \\ 3 & 2 & 1 & 3 & 2 & 2 & 0 & 2 & 15827.7583 & -0.0081 \\ 3 & 2 & 1 & 4 & 2 & 2 & 0 & 3 & 15827.7398 & 0.0065 \\ 2 & 1 & 2 & 1 & 1 & 1 & 1 & 0 & 9771.4666 & 0.0059 \\ 2 & 1 & 2 & 3 & 1 & 1 & 1 & 2 & 9771.4834 & -0.0004 \\ 3 & 1 & 3 & 3 & 2 & 1 & 2 & 3 & 14597.6997 & 0.0029 \\ 3 & 1 & 3 & 2 & 2 & 1 & 2 & 1 & 14597.6471 & -0.0057 \\ 3 & 1 & 3 & 3 & 2 & 1 & 2 & 2 & 14597.6640 & 0.0022 \\ 3 & 1 & 3 & 4 & 2 & 1 & 2 & 3 & 14597.6471 & -0.0028 \\ 3 & 0 & 3 & 2 & 2 & 0 & 2 & 2 & 15046.0669 & -0.0016 \\ 3 & 0 & 3 & 3 & 2 & 0 & 2 & 3 & 15046.1702 & -0.0024 \\ 3 & 0 & 3 & 2 & 2 & 0 & 2 & 1 & 15046.1335 & 0.0014 \\ 3 & 0 & 3 & 3 & 2 & 0 & 2 & 2 & 15046.1335 & 0.0018 \\ 3 & 0 & 3 & 4 & 2 & 0 & 2 & 3 & 15046.1235 & -0.0023 \\ 3 & 2 & 2 & 2 & 2 & 2 & 1 & 2 & 15436.9742 & -0.0023 \\ 3 & 2 & 2 & 3 & 2 & 2 & 1 & 3 & 15436.9429 & 0.0041 \\ 3 & 2 & 2 & 2 & 2 & 2 & 1 & 1 & 15436.9118 & -0.0061 \\ 3 & 2 & 2 & 3 & 2 & 2 & 1 & 2 & 15436.9742 & -0.0023 \\ 3 & 2 & 2 & 4 & 2 & 2 & 1 & 3 & 15436.9429 & 0.0041 \\ 3 & 1 & 3 & 2 & 2 & 0 & 2 & 1 & 15846.4625 & 0.0115 \\ 3 & 1 & 3 & 3 & 2 & 0 & 2 & 2 & 15846.4445 & -0.0063 \\ 3 & 1 & 3 & 4 & 2 & 0 & 2 & 3 & 15846.4445 & -0.0002 \\ 3 & 1 & 2 & 2 & 2 & 1 & 1 & 1 & 16143.8266 & 0.0026 \\ 3 & 1 & 2 & 3 & 2 & 1 & 1 & 2 & 16143.8394 & 0.0010 \\ 3 & 1 & 2 & 4 & 2 & 1 & 1 & 3 & 16143.8266 & -0.0007 \\ 2 & 2 & 1 & 2 & 1 & 1 & 1 & 1 & 16325.1537 & -0.0069 \\ 2 & 2 & 1 & 3 & 1 & 1 & 1 & 2 & 16325.1957 & 0.0000 \\ 2 & 2 & 0 & 2 & 1 & 1 & 1 & 1 & 16429.0548 & 0.0008 \\ 3 & 3 & 1 & 1 & 1 & 2 & 16429.0911 & -0.0013\end{array}$


Table S3: Fitted microwave transitions of the isotopomer of the $\mathrm{G}_{\mathrm{l}} \mathrm{CM} / \mathrm{G}_{\mathrm{r}} \mathrm{MC}$ conformer of butan-2,3-diol with deuteration at the proton acceptor hydroxyl group.

\begin{tabular}{|c|c|c|c|c|c|c|c|c|c|}
\hline "ا & $K_{a}^{\prime}$ & $K_{c}^{\prime}$ & $F^{\prime}$ & $J^{\prime \prime}$ & $K_{a}{ }^{\prime \prime}$ & $K_{c}{ }^{\prime \prime}$ & $F^{\prime \prime}$ & $v_{\text {obs }} / \mathrm{MHz}$ & $v_{\mathrm{obs}}-v_{\mathrm{cald}} / \mathrm{MHz}$ \\
\hline 1 & 0 & 1 & 1 & 0 & 0 & 0 & 1 & 5024.2599 & 0.0035 \\
\hline 1 & 0 & 1 & 0 & 0 & 0 & 0 & 1 & 5024.0937 & 0.0019 \\
\hline 1 & 0 & 1 & 2 & 0 & 0 & 0 & 1 & 5024.1903 & -0.0003 \\
\hline 1 & 1 & 0 & 1 & 0 & 0 & 0 & 1 & 7375.0210 & -0.0014 \\
\hline 1 & 1 & 0 & 0 & 0 & 0 & 0 & 1 & 7375.1268 & 0.0057 \\
\hline 1 & 1 & 0 & 2 & 0 & 0 & 0 & 1 & 7375.0603 & -0.0016 \\
\hline 1 & 1 & 1 & 0 & 0 & 0 & 0 & 1 & 6907.7024 & -0.0040 \\
\hline 1 & 1 & 1 & 1 & 0 & 0 & 0 & 1 & 6907.6459 & 0.0055 \\
\hline 1 & 1 & 1 & 2 & 0 & 0 & 0 & 1 & 6907.6670 & 0.0002 \\
\hline 2 & 1 & 2 & 2 & 1 & 1 & 1 & 1 & 9581.0579 & 0.0020 \\
\hline 2 & 1 & 2 & 3 & 1 & 1 & 1 & 2 & 9580.9867 & -0.0006 \\
\hline 2 & 0 & 2 & 1 & 1 & 0 & 1 & 0 & 9971.7398 & -0.0098 \\
\hline 2 & 0 & 2 & 3 & 1 & 0 & 1 & 2 & 9971.6915 & 0.0014 \\
\hline 2 & 1 & 1 & 2 & 1 & 1 & 0 & 1 & 10515.8264 & -0.0003 \\
\hline 2 & 1 & 1 & 3 & 1 & 1 & 0 & 2 & 10515.7589 & -0.0000 \\
\hline 2 & 1 & 2 & 1 & 1 & 0 & 1 & 1 & 11464.3712 & -0.0029 \\
\hline 2 & 1 & 2 & 2 & 1 & 0 & 1 & 2 & 11464.5020 & -0.0037 \\
\hline 2 & 1 & 2 & 1 & 1 & 0 & 1 & 0 & 11464.5460 & 0.0072 \\
\hline 2 & 1 & 2 & 3 & 1 & 0 & 1 & 2 & 11464.4648 & 0.0013 \\
\hline 2 & 1 & 1 & 1 & 1 & 0 & 1 & 1 & 12866.5507 & 0.0020 \\
\hline 2 & 1 & 1 & 1 & 1 & 0 & 1 & 0 & 12866.7153 & 0.0020 \\
\hline 2 & 1 & 1 & 2 & 1 & 0 & 1 & 1 & 12866.5918 & -0.0009 \\
\hline 2 & 1 & 1 & 3 & 1 & 0 & 1 & 2 & 12866.6294 & -0.0009 \\
\hline 3 & 0 & 3 & 3 & 2 & 1 & 2 & 2 & 13285.7975 & 0.0044 \\
\hline 3 & 0 & 3 & 4 & 2 & 1 & 2 & 3 & 13285.7608 & -0.0007 \\
\hline
\end{tabular}




$\begin{array}{cccccccccc}J^{\prime} & K_{a}^{\prime} & K_{c}^{\prime} & F^{\prime} & J^{\prime \prime} & K_{a}^{\prime \prime} & K_{c}^{\prime \prime} & F^{\prime \prime} & v_{\mathrm{obs}} / \mathrm{MHz} & v_{\mathrm{obs}}{ }^{-} v_{\mathrm{cald}} / \mathrm{MHz} \\ 3 & 1 & 3 & 3 & 2 & 1 & 2 & 3 & 14326.9750 & -0.0008 \\ 3 & 1 & 3 & 3 & 2 & 1 & 2 & 2 & 14326.9387 & 0.0052 \\ 3 & 1 & 3 & 4 & 2 & 1 & 2 & 3 & 14326.9084 & -0.0051 \\ 3 & 0 & 3 & 2 & 2 & 0 & 2 & 2 & 14778.4368 & -0.0014 \\ 3 & 0 & 3 & 3 & 2 & 0 & 2 & 2 & 14778.5352 & -0.0027 \\ 3 & 0 & 3 & 4 & 2 & 0 & 2 & 3 & 14778.5352 & 0.0004 \\ 3 & 2 & 2 & 3 & 2 & 2 & 1 & 2 & 15072.5994 & -0.0011 \\ 3 & 2 & 2 & 4 & 2 & 2 & 1 & 3 & 15072.5301 & 0.0002 \\ 2 & 2 & 1 & 2 & 1 & 1 & 0 & 2 & 16166.0963 & 0.0023 \\ 2 & 2 & 1 & 3 & 1 & 1 & 0 & 2 & 16166.1652 & 0.0006 \\ 3 & 2 & 1 & 2 & 2 & 2 & 0 & 1 & 15366.4752 & -0.0012 \\ 3 & 2 & 1 & 3 & 2 & 2 & 0 & 2 & 15366.5848 & -0.0008 \\ 3 & 2 & 1 & 4 & 2 & 2 & 0 & 3 & 15366.5179 & 0.0024 \\ 3 & 1 & 3 & 3 & 2 & 0 & 2 & 3 & 15819.7481 & -0.0010 \\ 3 & 1 & 3 & 2 & 2 & 0 & 2 & 1 & 15819.7090 & 0.0046 \\ 3 & 1 & 3 & 3 & 2 & 0 & 2 & 2 & 15819.6798 & 0.0015 \\ 3 & 1 & 3 & 4 & 2 & 0 & 2 & 3 & 15819.6798 & -0.0071 \\ 2 & 2 & 0 & 2 & 1 & 1 & 0 & 1 & 16242.8165 & -0.0046 \\ 2 & 2 & 0 & 3 & 1 & 1 & 0 & 2 & 16242.8546 & 0.0022 \\ 2 & 2 & 0 & 1 & 1 & 1 & 1 & 1 & 16710.3116 & -0.0017 \\ 2 & 2 & 0 & 2 & 1 & 1 & 1 & 1 & 16710.2056 & 0.0025 \\ 2 & 2 & 0 & 3 & 1 & 1 & 1 & 2 & 16710.2464 & -0.0012\end{array}$




\section{Microwave transitions of homochiral butan-2,3-diol.}

Table S4: Fitted microwave transitions of the parent isotopomer of the GtCM conformer of butan-2,3-diol.

\begin{tabular}{|c|c|c|c|c|c|c|c|c|c|}
\hline & $K_{a}{ }^{\prime}$ & $K_{c}^{\prime}$ & $v^{\prime a}$ & $J^{\prime \prime}$ & $K_{a}^{\prime \prime}$ & $K_{c}{ }^{\prime \prime}$ & $v^{\prime \prime a}$ & $v_{\mathrm{obs}} / \mathrm{MHz}$ & $v_{\mathrm{obs}}-v_{\mathrm{calc}} / \mathrm{MHz}$ \\
\hline 3 & 1 & 2 & 0 & 3 & 0 & 3 & 0 & 6748.4595 & 0.0004 \\
\hline 3 & 1 & 2 & 1 & 3 & 0 & 3 & 1 & 6747.9610 & -0.0004 \\
\hline 5 & 3 & 2 & 1 & 5 & 2 & 3 & 1 & 7323.6892 & 0.0005 \\
\hline 5 & 3 & 2 & 0 & 5 & 2 & 3 & 0 & 7324.1719 & 0.0007 \\
\hline 4 & 3 & 1 & 0 & 4 & 2 & 2 & 0 & 7752.8982 & -0.0003 \\
\hline$\angle$ & 3 & 1 & 1 & 4 & 2 & 2 & 1 & 7754.0804 & 0.0006 \\
\hline 2 & 2 & 1 & 0 & 2 & 1 & 2 & 0 & 7764.7910 & -0.0001 \\
\hline 2 & 2 & 1 & 1 & 2 & 1 & 2 & 1 & 7764.1571 & 0.0002 \\
\hline 2 & 0 & 2 & 0 & 1 & 1 & 1 & 0 & 8205.2069 & 0.0013 \\
\hline 2 & 0 & 2 & 1 & 1 & 1 & 1 & 1 & 8207.1127 & 0.0019 \\
\hline 3 & 3 & 0 & 0 & 3 & 2 & 1 & 0 & 8778.6604 & 0.0002 \\
\hline 3 & 3 & 0 & 1 & 3 & 2 & 1 & 1 & 8779.3344 & 0.0002 \\
\hline 3 & 2 & 2 & 1 & 3 & 1 & 3 & 1 & 9614.4980 & -0.0001 \\
\hline 3 & 2 & 2 & 0 & 3 & 1 & 3 & 0 & 9615.5415 & 0.0001 \\
\hline 4 & 1 & 3 & 1 & 4 & 0 & 4 & 1 & 10297.9331 & -0.0012 \\
\hline 4 & 1 & 3 & 0 & 4 & 0 & 4 & 0 & 10299.0309 & 0.0001 \\
\hline 3 & 3 & 1 & 0 & 3 & 2 & 2 & 0 & 10448.1415 & -0.0011 \\
\hline 3 & 3 & 1 & 1 & 3 & 2 & 2 & 1 & 10449.1759 & -0.0008 \\
\hline 2 & 1 & 2 & 0 & 1 & 0 & 1 & 0 & 10535.0964 & -0.0012 \\
\hline 2 & 1 & 2 & 1 & 1 & 0 & 1 & 1 & 10535.9336 & -0.0002 \\
\hline 3 & 1 & 2 & 1 & 2 & 2 & 1 & 1 & 11970.6411 & -0.0000 \\
\hline 3 & 1 & 2 & 0 & 2 & 2 & 1 & 0 & 11971.0377 & 0.0004 \\
\hline
\end{tabular}




$\begin{array}{cccccccccc}J^{\prime} & K_{a}^{\prime} & K_{c}^{\prime} & v^{\prime a} & J^{\prime \prime} & K_{a}^{\prime \prime} & K_{c}{ }^{\prime \prime} & v^{\prime \prime a} & v_{\mathrm{obs}} / \mathrm{MHz} & v_{\mathrm{obs}}-v_{\mathrm{calc}} / \mathrm{MHz} \\ 4 & 2 & 3 & 0 & 4 & 0 & 4 & 1 & 11157.3701 & 0.0006 \\ 4 & 2 & 3 & 1 & 4 & 1 & 4 & 1 & 12052.2026 & -0.0004 \\ 4 & 2 & 3 & 0 & 4 & 1 & 4 & 0 & 12053.7252 & -0.0003 \\ 3 & 1 & 3 & 0 & 2 & 1 & 2 & 1 & 12315.6267 & -0.0005 \\ 3 & 0 & 3 & 0 & 2 & 0 & 2 & 1 & 12801.9343 & -0.0010 \\ 3 & 0 & 3 & 1 & 2 & 1 & 2 & 1 & 12986.8360 & -0.0007 \\ 3 & 0 & 3 & 0 & 2 & 1 & 2 & 0 & 12987.3696 & 0.0003 \\ 4 & 2 & 3 & 1 & 4 & 0 & 4 & 0 & 13179.7818 & -0.0005 \\ 5 & 1 & 4 & 0 & 5 & 0 & 5 & 0 & 14098.4468 & -0.0010 \\ 5 & 1 & 4 & 1 & 5 & 0 & 5 & 1 & 14102.3872 & -0.0010 \\ 3 & 1 & 3 & 1 & 2 & 0 & 2 & 1 & 14154.8291 & -0.0006 \\ 3 & 1 & 3 & 0 & 2 & 0 & 2 & 0 & 14155.6227 & -0.0005 \\ 3 & 2 & 2 & 0 & 2 & 2 & 1 & 1 & 14167.0120 & 0.0004 \\ 3 & 1 & 3 & 1 & 2 & 1 & 2 & 0 & 14340.2638 & 0.0001 \\ 3 & 0 & 3 & 1 & 2 & 0 & 2 & 0 & 14826.8324 & -0.0003 \\ 2 & 2 & 0 & 0 & 1 & 1 & 0 & 1 & 15111.1885 & -0.0000 \\ 3 & 1 & 2 & 0 & 2 & 1 & 1 & 1 & 15466.3483 & 0.0003 \\ 3 & 2 & 1 & 0 & 2 & 2 & 0 & 1 & 15531.3024 & 0.0003 \\ 2 & 2 & 1 & 0 & 1 & 1 & 0 & 0 & 15711.0931 & -0.0006 \\ 2 & 2 & 1 & 1 & 1 & 1 & 0 & 1 & 15712.0010 & 0.0001 \\ 2 & 2 & 1 & 0 & 1 & 1 & 1 & 1 & 15786.4683 & 0.0004 \\ 3 & 2 & 2 & 1 & 2 & 2 & 1 & 0 & 16189.9708 & 0.0001 \\ 4 & 1 & 4 & 0 & 3 & 1 & 3 & 1 & 16457.0573 & 0.0001 \\ 4 & 0 & 4 & 0 & 3 & 0 & 3 & 1 & 16682.2110 & -0.0002 \\ 2 & 2 & 0 & 1 & 1 & 1 & 0 & 0 & 17134.3878 & -0.0006 \\ 2 & 2 & 0 & 0 & 1 & 1 & 1 & 0 & 17208.5453 & -0.0008 \\ 2 & 2 & 0 & 1 & 1 & 1 & 1 & 1 & 17209.7617 & -0.0010 \\ 4 & 0 & 4 & 0 & 3 & 1 & 3 & 0 & 17353.4213 & 0.0006 \\ 4 & 0 & 4 & 1 & 3 & 1 & 3 & 1 & 17353.4122 & -0.0011 \\ & 2 & 1 & 2 & 1 & 1 & 0 & 17489.7610 & 0.0002\end{array}$




$\begin{array}{cccccccccc}J^{\prime} & K_{a}^{\prime} & K_{c}^{\prime} & v^{\prime a} & J^{\prime \prime} & K_{a}^{\prime \prime} & K_{c}^{\prime \prime} & v^{\prime \prime a} & v_{\mathrm{obs}} / \mathrm{MHz} & v_{\mathrm{obs}}-v_{\mathrm{cald}} / \mathrm{MHz} \\ 3 & 2 & 1 & 1 & 2 & 2 & 0 & 0 & 17554.7657 & 0.0006 \\ 2 & 2 & 1 & 1 & 1 & 1 & 1 & 0 & 17809.3585 & 0.0000 \\ 4 & 1 & 4 & 1 & 3 & 0 & 3 & 1 & 17809.7897 & -0.0008 \\ 4 & 1 & 4 & 0 & 3 & 0 & 3 & 0 & 17809.9525 & 0.0008 \\ 4 & 1 & 3 & 0 & 3 & 2 & 2 & 0 & 18036.9099 & -0.0002 \\ 4 & 1 & 3 & 1 & 3 & 2 & 2 & 1 & 18036.8502 & 0.0007 \\ 4 & 1 & 4 & 1 & 3 & 1 & 3 & 0 & 18481.0001 & 0.0001 \\ 4 & 0 & 4 & 1 & 3 & 0 & 3 & 0 & 18706.3078 & 0.0001 \\ 6 & 4 & 2 & 1 & 6 & 3 & 3 & 1 & 10609.5591 & -0.0001 \\ 6 & 4 & 2 & 0 & 6 & 3 & 3 & 0 & 10605.3428 & -0.0013 \\ 4 & 4 & 1 & 0 & 4 & 3 & 2 & 0 & 13826.3032 & -0.0005 \\ 4 & 4 & 1 & 1 & 4 & 3 & 2 & 1 & 13825.9295 & -0.0006 \\ 5 & 4 & 2 & 0 & 5 & 3 & 3 & 0 & 14069.3802 & 0.0004 \\ 5 & 4 & 2 & 1 & 5 & 3 & 3 & 1 & 14071.0964 & 0.0011 \\ 5 & 2 & 4 & 0 & 5 & 1 & 5 & 0 & 14930.0083 & 0.0004 \\ 5 & 2 & 4 & 1 & 5 & 1 & 5 & 1 & 14933.6355 & 0.0002 \\ 4 & 4 & 0 & 0 & 4 & 3 & 1 & 0 & 13177.3891 & 0.0002 \\ 4 & 4 & 0 & 1 & 4 & 3 & 1 & 1 & 13176.7838 & 0.0001 \\ 2 & 1 & 1 & 0 & 1 & 0 & 1 & 1 & 12780.9716 & 0.0006 \\ 2 & 1 & 1 & 1 & 1 & 0 & 1 & 0 & 14804.5793 & 0.0013 \\ 5 & 4 & 1 & 1 & 5 & 3 & 3 & 0 & 15270.5920 & 0.0005 \\ 5 & 4 & 1 & 0 & 5 & 3 & 3 & 1 & 13248.6144 & 0.0008 \\ 5 & 3 & 3 & 1 & 5 & 2 & 4 & 1 & 12940.1138 & 0.0010 \\ 5 & 3 & 3 & 0 & 5 & 2 & 4 & 0 & 12945.6141 & 0.0008 \\ 5 & 4 & 1 & 1 & 5 & 3 & 2 & 1 & 12043.4786 & 0.0005 \\ 5 & 4 & 1 & 0 & 5 & 3 & 2 & 0 & 12042.3641 & 0.0001 \\ 5 & 4 & 2 & 1 & 5 & 3 & 2 & 0 & 12864.8464 & 0.0006 \\ 5 & 5 & 0 & 1 & 5 & 4 & 1 & 1 & 17397.3177 & 0.0003 \\ 5 & 5 & 0 & 0 & 5 & 4 & 1 & 0 & 17397.0725 & 0.0011 \\ 5 & 5 & 1 & 0 & 5 & 4 & 2 & 0 & 17582.1092 & -0.0005\end{array}$




$\begin{array}{cccccccccc}J^{\prime} & K_{a}^{\prime} & K_{c}^{\prime} & v^{\prime a} & J^{\prime \prime} & K_{a}^{\prime \prime} & K_{c}{ }^{\prime \prime} & v^{\prime \prime a} & v_{\mathrm{obs}} / \mathrm{MHz} & v_{\mathrm{obs}}{ }^{-} v_{\mathrm{calc}} / \mathrm{MHz} \\ 5 & 5 & 1 & 1 & 5 & 4 & 2 & 1 & 17582.4500 & -0.0007 \\ 7 & 4 & 4 & 1 & 7 & 3 & 5 & 1 & 16096.2741 & 0.0002 \\ 7 & 4 & 4 & 0 & 7 & 3 & 5 & 0 & 16094.9755 & 0.0009 \\ 8 & 5 & 4 & 1 & 8 & 4 & 5 & 1 & 18056.2262 & -0.0017 \\ 8 & 5 & 4 & 0 & 8 & 4 & 5 & 0 & 18041.4574 & 0.0009 \\ 8 & 5 & 3 & 1 & 8 & 4 & 4 & 1 & 13522.2503 & -0.0000 \\ 8 & 5 & 3 & 0 & 8 & 4 & 4 & 0 & 13508.8206 & 0.0000 \\ 8 & 5 & 3 & 0 & 8 & 4 & 5 & 1 & 17953.2310 & -0.0011 \\ 6 & 3 & 4 & 1 & 6 & 1 & 5 & 0 & 16484.7566 & 0.0002 \\ 6 & 3 & 4 & 0 & 6 & 1 & 5 & 1 & 14463.0537 & 0.0015 \\ 2 & 1 & 1 & 1 & 1 & 1 & 0 & 0 & 12215.7828 & -0.0002 \\ 2 & 1 & 1 & 0 & 1 & 1 & 0 & 1 & 10192.8810 & -0.0002 \\ 8 & 5 & 4 & 0 & 8 & 4 & 4 & 1 & 11578.2059 & 0.0001 \\ 8 & 5 & 4 & 1 & 8 & 4 & 4 & 0 & 13611.8161 & -0.0002\end{array}$

${ }^{a} v=0$ signifies the lower and $v=1$ signifies the upper tunnelling state. 
Table S5: Fitted microwave transitions of the isotopomer of the GtCM conformer of butan-2,3-diol with deuteration at the proton donor hydroxyl group.

\begin{tabular}{|c|c|c|c|c|c|c|c|c|c|}
\hline$J^{\prime}$ & $K_{a}^{\prime}$ & $K_{c}^{\prime}$ & $F^{\prime}$ & $J^{\prime \prime}$ & $K_{a}{ }^{\prime \prime}$ & $K_{c}{ }^{\prime \prime}$ & $F^{\prime \prime}$ & $v_{\mathrm{obs}} / \mathrm{MHz}$ & $v_{\text {obs }}-v_{\text {cald }} / \mathrm{MHz}$ \\
\hline 1 & 1 & 1 & 0 & 0 & 0 & 0 & 1 & 6394.096 & 0.0008 \\
\hline 1 & 1 & 1 & 1 & 0 & 0 & 0 & 1 & 6394.190 & -0.00148 \\
\hline 1 & 1 & 1 & 2 & 0 & 0 & 0 & 1 & 6394.153 & 0.00015 \\
\hline 1 & 1 & 0 & 0 & 0 & 0 & 0 & 1 & 7499.306 & -0.00254 \\
\hline 1 & 1 & 0 & 1 & 0 & 0 & 0 & 1 & 7499.199 & 0.00076 \\
\hline 1 & 1 & 0 & 2 & 0 & 0 & 0 & 1 & 7499.243 & 0.00054 \\
\hline 2 & 1 & 2 & 1 & 1 & 1 & 1 & 0 & 8930.143 & 0.00165 \\
\hline 2 & 1 & 2 & 3 & 1 & 1 & 1 & 2 & 8930.111 & 0.00185 \\
\hline 3 & 2 & 2 & 2 & 3 & 1 & 3 & 2 & 9343.704 & 0.00408 \\
\hline 3 & 2 & 2 & 3 & 3 & 1 & 3 & 3 & 9343.623 & -0.00129 \\
\hline 3 & 2 & 2 & 4 & 3 & 1 & 3 & 4 & 9343.676 & -0.00429 \\
\hline 2 & 1 & 2 & 2 & 1 & 0 & 1 & 1 & 10306.70 & -0.00113 \\
\hline 2 & 1 & 2 & 3 & 1 & 0 & 1 & 2 & 10306.66 & 0.00214 \\
\hline 3 & 1 & 3 & 2 & 2 & 1 & 2 & 1 & 13153.99 & -0.00771 \\
\hline 3 & 1 & 3 & 3 & 2 & 1 & 2 & 2 & 13154.00 & 0.00195 \\
\hline 3 & 1 & 3 & 4 & 2 & 1 & 2 & 3 & 13153.99 & -0.0012 \\
\hline 3 & 1 & 2 & 2 & 2 & 1 & 1 & 1 & 16343.52 & -0.00314 \\
\hline 3 & 1 & 2 & 3 & 2 & 1 & 1 & 2 & 16343.55 & 0.0037 \\
\hline 3 & 1 & 2 & 4 & 2 & 1 & 1 & 3 & 16343.53 & 0.00065 \\
\hline 2 & 2 & 0 & 1 & 1 & 1 & 1 & 0 & 16823.78 & 0.00133 \\
\hline 2 & 2 & 0 & 2 & 1 & 1 & 1 & 1 & 16823.64 & 0.00108 \\
\hline 2 & 2 & 0 & 3 & 1 & 1 & 1 & 2 & 16823.71 & -0.00078 \\
\hline 4 & 0 & 4 & 4 & 3 & 0 & 3 & 3 & 17409.98 & 0.00262 \\
\hline 4 & 0 & 4 & 5 & 3 & 0 & 3 & 4 & 17409.96 & -0.00203 \\
\hline 4 & 1 & 4 & 4 & 3 & 0 & 3 & 3 & 17497.43 & 0.00352 \\
\hline 4 & 1 & 4 & 5 & 3 & 0 & 3 & 4 & 17497.40 & -0.00243 \\
\hline
\end{tabular}


Table S6: Fitted microwave transitions of the isotopomer of the GtCM conformer of butan-2,3-diol with deuteration at the proton acceptor hydroxyl group.

\begin{tabular}{|c|c|c|c|c|c|c|c|c|c|}
\hline$J^{\prime}$ & $K_{a}^{\prime}$ & $K_{c}^{\prime}$ & $F^{\prime}$ & $J^{\prime \prime}$ & $K_{a}^{\prime \prime}$ & $K_{c}^{\prime \prime}$ & $F^{\prime \prime}$ & $v_{\mathrm{obs}} / \mathrm{MHz}$ & $v_{\mathrm{obs}^{-}} v_{\text {calc }} / \mathrm{MHz}$ \\
\hline 1 & 0 & 1 & 0 & 0 & 0 & 0 & 1 & 4928.2997 & -0.0023 \\
\hline 1 & 0 & 1 & 1 & 0 & 0 & 0 & 1 & 4928.4271 & -0.0001 \\
\hline 1 & 0 & 1 & 2 & 0 & 0 & 0 & 1 & 4928.3768 & -0.0003 \\
\hline 1 & 1 & 1 & 0 & 0 & 0 & 0 & 1 & 6446.3248 & 0.0006 \\
\hline 1 & 1 & 1 & 1 & 0 & 0 & 0 & 1 & 6446.2309 & -0.0008 \\
\hline 1 & 1 & 1 & 2 & 0 & 0 & 0 & 1 & 6446.2679 & -0.0008 \\
\hline 1 & 1 & 0 & 2 & 0 & 0 & 0 & 1 & 7493.3661 & 0.0010 \\
\hline 2 & 1 & 1 & 2 & 1 & 1 & 0 & 2 & 10903.8825 & -0.0048 \\
\hline 2 & 1 & 1 & 1 & 1 & 1 & 0 & 0 & 10903.8115 & 0.0055 \\
\hline 2 & 1 & 1 & 2 & 1 & 1 & 0 & 1 & 10903.9006 & 0.0003 \\
\hline 2 & 1 & 1 & 3 & 1 & 1 & 0 & 2 & 10903.8464 & -0.0012 \\
\hline 2 & 0 & 2 & 1 & 1 & 0 & 1 & 1 & 9471.9981 & 0.0009 \\
\hline 2 & 0 & 2 & 2 & 1 & 0 & 1 & 2 & 9472.1131 & -0.0012 \\
\hline 2 & 0 & 2 & 1 & 1 & 0 & 1 & 0 & 9472.1238 & 0.0014 \\
\hline 2 & 0 & 2 & 3 & 1 & 0 & 1 & 2 & 9472.0721 & 0.0009 \\
\hline 2 & 1 & 2 & 2 & 1 & 1 & 1 & 1 & 8809.7094 & 0.0013 \\
\hline 2 & 1 & 2 & 3 & 1 & 1 & 1 & 2 & 8809.6565 & -0.0006 \\
\hline 2 & 1 & 2 & 1 & 1 & 0 & 1 & 0 & 10327.6171 & 0.0010 \\
\hline 2 & 1 & 2 & 3 & 1 & 0 & 1 & 2 & 10327.5472 & -0.0015 \\
\hline 3 & 1 & 2 & 3 & 2 & 1 & 1 & 2 & 16051.0865 & 0.0009 \\
\hline 3 & 1 & 2 & 4 & 2 & 1 & 1 & 3 & 16051.0745 & -0.0010 \\
\hline 3 & 0 & 3 & 3 & 2 & 1 & 2 & 2 & 12642.5773 & 0.0016 \\
\hline 3 & 0 & 3 & 4 & 2 & 1 & 2 & 3 & 12642.5522 & -0.0021 \\
\hline 4 & 2 & 3 & 3 & 4 & 0 & 4 & 3 & 11950.4214 & -0.0003 \\
\hline 4 & 2 & 3 & 4 & 4 & 0 & 4 & 4 & 11950.4040 & -0.0026 \\
\hline 4 & 2 & 3 & 5 & 4 & 0 & 4 & 5 & 11950.4214 & 0.0028 \\
\hline
\end{tabular}


Table S7. Structural coordinates of the $\mathrm{G}_{1} \mathrm{CM} / \mathrm{G}_{\mathrm{r}} \mathrm{MC}$ conformer of heterochiral butan-2,3diol derived from MP2 6-311++G** ab initio calculations (after counterpoise correction).

$\begin{array}{cccc}\text { Atom } & a & b & c \\ \text { C } & 0.7022 & -0.0364 & -0.3224 \\ \text { C } & 1.5807 & 1.1338 & 0.0802 \\ \text { C } & -0.6803 & 0.0042 & 0.3181 \\ \text { C } & -1.5015 & 1.2213 & -0.0785 \\ \text { O } & 1.3779 & -1.2232 & 0.079 \\ \text { O } & -1.3157 & -1.2083 & -0.1198 \\ \text { H } & 0.558 & -0.0419 & -1.4146 \\ \text { H } & -0.5416 & -0.0322 & 1.4084 \\ \text { H } & -2.5189 & 1.1382 & 0.3174 \\ \text { H } & -1.0636 & 2.1402 & 0.3203 \\ \text { H } & -1.5636 & 1.2945 & -1.1684 \\ \text { H } & 2.5898 & 0.9704 & -0.3053 \\ \text { H } & 1.203 & 2.0755 & -0.3257 \\ \text { H } & 1.6376 & 1.2072 & 1.1707 \\ \text { H } & 0.7332 & -1.9326 & -0.0304 \\ \text { H } & -2.138 & -1.3045 & 0.3692\end{array}$


Table S8. Structural coordinates of the $\mathrm{G}_{1} \mathrm{CM} / \mathrm{G}_{\mathrm{r}} \mathrm{MC}$ conformer of homochiral butan-2,3-diol derived from MP2 6-311++G** ab initio calculations (after counterpoise correction).

$\begin{array}{cccc}\text { Atom } & a & b & c \\ \text { C } & 0.7022 & -0.0364 & -0.3224 \\ \text { C } & 1.5807 & 1.1338 & 0.0802 \\ \text { C } & -0.6803 & 0.0042 & 0.3181 \\ \text { C } & -1.5015 & 1.2213 & -0.0785 \\ \text { O } & 1.3779 & -1.2232 & 0.079 \\ \text { O } & -1.3157 & -1.2083 & -0.1198 \\ \text { H } & 0.558 & -0.0419 & -1.4146 \\ \text { H } & -0.5416 & -0.0322 & 1.4084 \\ \text { H } & -2.5189 & 1.1382 & 0.3174 \\ \text { H } & -1.0636 & 2.1402 & 0.3203 \\ \text { H } & -1.5636 & 1.2945 & -1.1684 \\ \text { H } & 2.5898 & 0.9704 & -0.3053 \\ \text { H } & 1.203 & 2.0755 & -0.3257 \\ \text { H } & 1.6376 & 1.2072 & 1.1707 \\ \text { H } & 0.7332 & -1.9326 & -0.0304 \\ \text { H } & -2.138 & -1.3045 & 0.3692\end{array}$

